\title{
A novel photoactivatable tool for intermediate filament disruption indicates a role for keratin filaments in early embryogenesis
}

Running title: Optogenetic Perturbation of Intermediate Filament Networks

Rucha Sanghvi-Shah ${ }^{1}$, Shalaka Paranjpe ${ }^{1}$, Jiyeon Baek ${ }^{1}$, Radek Dobrowolski ${ }^{1,2,3}$, and Gregory F. Weber ${ }^{1}$

\section{Affiliations:}

${ }^{1}$ Department of Biological Sciences, Rutgers University, Newark, NJ 07102, USA

Glenn Biggs Institute for Alzheimer's \& Neurodegenerative Diseases, University of Texas Health Sciences Center, San Antonio, TX, USA

${ }^{3}$ Department of Cell Systems and Anatomy, University of Texas Health Science Center, San Antonio, TX, USA

${ }^{*}$ Corresponding author:

Gregory F. Weber, PhD

gregory.weber@rutgers.edu

Tel: 973-353-5532 


\section{Abstract}

The significance of cytoplasmic intermediate filament proteins has previously been examined largely through various genetic approaches, including knockdown, knockout and transgenic overexpression. Few studies to date have attempted to examine the role of specifically the filamentous intermediate filament network in orchestrating various cell functions. To directly assess the role of the filamentous keratin intermediate filament network in regulation of cellular behavior, we created a Photoㅅctivatable disruptor of keratin Intermediate Filaments (PA-dIF). This genetically encoded construct consists of a peptide derived from the 2B2 region of Keratin 8 fused to the photosensitive LOV2 domain from Avena sativa phototropin-1. Upon $458 \mathrm{~nm}$ photoirradiation, PA-dIF disrupts keratin intermediate filaments in multiple species and cell types. Marked remodeling of the keratin intermediate filament network accompanies collective cellular morphogenetic movements that occur during gastrulation and neurulation in the Xenopus laevis frog embryo. Light-based activation of PA-dIF was able to disrupt keratin intermediate filaments in Xenopus cells and lead to tissue-specific disruption of morphogenetic processes. Altogether our data show a fundamental requirement for keratin intermediate filaments in orchestrating morphogenetic movements during early embryonic development that have yet to be revealed in other model systems. Moreover, our data validate the utility of a new genetically encoded photoactivatable tool for the disruption and examination of intermediate filaments.

\section{Introduction}

Intermediate filament proteins polymerize to form cytoskeletal networks present in almost all metazoan cells (Herrmann and Strelkov, 2011). The proteins that constitute this family are expressed in a cell and tissue specific manner. Intermediate filament proteins can broadly be partitioned into two groups based on where they assemble into polymerized filaments. Lamins, the primordial ancestral intermediate filament proteins (Dodemont and Riemer, 1990; 
Döring and Stick, 1990; Peter and Stick, 2015), assemble into a filamentous network in the nucleus. All other intermediate filament proteins assemble as filaments in the cytoplasm. Cytoplasmic intermediate filaments form five subfamilies that collectively include keratins, vimentin, desmin, neurofilaments, among many others. In addition to their conserved amino acid sequences, motifs and structure, a key defining feature of intermediate filaments is that they convey mechanical strength to cells and cellular structures. Through linkage to cell adhesions, association with the nuclear membrane, and interactions with other cytoskeletal networks, intermediate filaments have important roles in regulating cell shape, nuclear morphology, and consequently cellular function (Sanghvi-Shah and Weber, 2017). The diversity of proteins, and the cytoplasmic filaments that they make, creates small but significant differences in assembly mechanics and the micromechanical properties of filaments (Block et al., 2015).

Keratin filaments polymerize as obligatory heterodimers, requiring both Type I acidic keratin and Type II basic keratin in a 1:1 stoichiometry (Steinert et al., 1976; Hatzfeld and Franke, 1985). These heterodimers associate in anti-parallel to form a tetramer. Tetramers associate laterally with other tetramers to constitute the simplest unit of intermediate filament assembly, the unit length filament (ULF). ULFs associate end-to-end to create a 10-12 nm diameter intermediate filament (Quinlan et al., 1984; Parry et al., 1985; Coulombe and Fuchs, 1990; Steinert, 1990; Martin et al., 2015). This model of the intermediate filament assembly process has largely been derived from in vitro work (Herrmann and Aebi, 2016) and comparatively few studies conducted in the cellular context (Helfand et al., 2011; Murray et al., 2014).

Non-epidermal epithelia prominently express Type II Keratin 8 (Krt8/K8) and Type I Keratins 18 and 19 (Krt18/K18 and Krt19/K19) to form K8-K18 and K8-K19 dimers (Franke et al., 1981). Keratin intermediate filaments may then be assembled from a combination of these dimers. Interestingly, Krt8, Krt18, and Krt19, but not vimentin, are also the first cytoplasmic 
intermediate filaments present and zygotically expressed in the developing embryo (Franz et al., 1983; Suzuki et al., 2017) yet functional roles for these keratin networks remain poorly defined.

Likewise, despite the ubiquity of intermediate filaments, their cellular functions remain poorly understood by comparison to actin microfilaments and microtubules. A variety of tools are readily available for altering actin and microtubule polymerization, which has allowed for major breakthroughs in their fields of research. In this study, we sought to develop a biomolecular tool that could be used to selectively disrupt intermediate filaments.

All intermediate filaments share a common tripartite structure that includes an a-helical rod domain flanked by head and tail regions at both ends. It is through the a-helical rod domain that dimerization occurs to form a coiled-coil. Of particular importance to intermediate filament dimerization is a highly conserved region at the C-terminal end of the coiled-coil domain, termed 2B2 (Hatzfeld and Weber, 1992). Mimetic 2B2 peptide segments incubated with intermediate filament proteins during in vitro assembly assays both inhibit the de novo assembly of filaments and can induce disassembly of existing filaments. These characteristics seem to be applicable to both vimentin and keratin alike (Kouklis et al., 1992; Steinert et al., 1993b, 1993a; Strelkov et al., 2002). Evidence also indicates that 2B2 peptides can disrupt intermediate filaments in living cells (Helfand et al., 2011).

Advances in optogenetics have enabled the production of genetically encoded proteins that can be activated or otherwise altered by exposure to specific wavelengths of light. The Light- $\underline{O} x y g e n-\underline{V}$ oltage sensing (LOV)-J $\alpha$ domain from Avena sativa phototropin-1 is one such module that has been used to create various photoswitchable proteins and light-sensitive biomolecular traps (Wu et al., 2009; Lungu et al., 2012; Zimmerman et al., 2016). Here, we have engineered a photoactivatable disruptor of intermediate filaments by fusing the 2B2 domain of Keratin 8 to the LOV-J $\alpha$ photosensitive module. Using this novel biomolecular tool, we demonstrate the ability to acutely disrupt intermediate filaments with subcellular spatial 
resolution, and identify important functions for keratin filaments during early embryonic development.

\section{Materials and Methods}

\section{Plasmid DNA construct design and production}

Xenopus keratin 8 plasmid C2-eGFP-Krt8 construct was a kind gift from Dr. Victoria Allan and was subcloned into $\mathrm{pCS}^{+}$previously (Weber et al., 2012). Keratin 19 plasmid pCS2+-eGFPKrt19 was made by Richard Mariani (Mariani et al., 2018). Photoㅅctivatable disruptor of

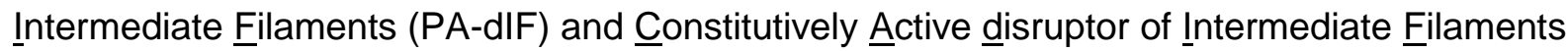
(CA-dIF) were generated by cloning commercially synthesized Flag-tagged LOV-J $\alpha$-2B2 (FlagPA-dIF) and LOV-Ja(I379E)-2B2 (Flag-CA-dIF) (Genewiz, NJ) into pCS2+ vector using EcoRI and Xhol restriction sites. Flag-tag was swapped for mCherry at the $\mathrm{N}$-terminus using Nhel and Bglll sites in pCS2+ Flag-PA/CA-dIF and C1-mCherry.

Plasmid DNA was prepared according to the manufacturer's protocol using NucleoBond Xtra Midi or Mini kit (Macherey-Nagel). Analytical and preparative restrictions were analyzed by agarose gel electrophoresis (0.8\% to $1 \%)$ prepared from agarose and $1 \times$ TAE running buffer (Tris/Acetate/EDTA: $40 \mathrm{mM}$ Tris-Acetate, $\mathrm{pH}$ 8.5, $2 \mathrm{mM}$ EDTA). For visualization of the DNA, either Gel Red (Biotium, \#41003) or ethidium bromide (Amersco, \#2810) were used and documented using Spectroline UV and UVP PhotoDoc-IT systems. 
Purification of DNA fragments from agarose gels or restriction digestions were performed with the Zymoclean Gel DNA Recovery kit (ZymoResearch, \#D4002) or Nucleospin Gel and PCR clean up (Macherey-Nagel, \#74060950) according to the manufacturer's instructions.

Concentration of restriction-digested and gel purified vector and insert DNA fragments was determined by A260 on a spectrophotometer. 1:3 to 1:10 molar ratio of vector:insert was used in ligation reactions. Standard ligation reactions were carried out using T4 DNA Ligase (New England Biolabs, \#MO202L) according to the manufacturer's instructions. The ligation was incubated for 45 minutes at room temperature or overnight at $15^{\circ} \mathrm{C}$.

For chemical transformation of the ligation reaction, 5-alpha (New England Biolabs, \#C2988J) or Express lq competent E. coli cells (New England Biolabs, \#C3037I) were used. The ligation reaction volume was added to $50 \mu \mathrm{l}$ of the competent cells in a pre-chilled $14 \mathrm{ml}$ round bottom tube on ice and incubated for 30 minutes. Cells were heat shocked at $42^{\circ} \mathrm{C}$ for exactly 2 min, followed by a further incubation on ice for 2 minutes. SOC medium $(1 \mathrm{ml})$ was added and the transformed cells were incubated for $60 \mathrm{~min}$ at $37^{\circ} \mathrm{C}$ in a rotating shaker ( 250 rpm) for recovery. Subsequently, different quantities of transformed cells were spread onto warm selection plates (LB agar plates supplemented with the appropriate antibiotic; ampicillin or kanamycin) and colonies were allowed to grow overnight at $37^{\circ} \mathrm{C}$.

\section{Software analyses of protein structure}

Protein sequences were analyzed for hydrophobic moment and amphipathicity using Heliquest (http://heliquest.ipmc.cnrs.fr/) (Gautier et al., 2008). Predicted secondary structure and 3D models of protein constructs were generated using $\mathrm{PHYRE}^{2}$ (http://www.sbg.bio.ic.ac.uk/phyre2/html/page.cgi?id=index) (Kelley et al., 2015). 


\section{In vitro transcription}

To synthesize RNA for microinjection, $6 \mu \mathrm{g}$ of $\mathrm{pCS} 2^{+}$-PA-dIF, pCS2 ${ }^{+}$-CA-dIF, or pCS2+-EGFPKrt8 DNA was linearized with Notl restriction enzyme (New England Biolabs) at $37^{\circ} \mathrm{C}$ overnight. pCS2 ${ }^{+}$-EGFP-Krt19 DNA was linearized with BssHII (New England Biolabs) at $50^{\circ} \mathrm{C}$ overnight. Digested DNA was extracted with phenol:chloroform:isoamyl alcohol (25:24:1) (Invitrogen) and precipitated with $3 \mathrm{M}$ sodium acetate solution and 100\% ethanol and incubated overnight at $20^{\circ} \mathrm{C}$. DNA was pelleted by centrifugation at $14000 \mathrm{~g}$ for $10 \mathrm{~min}$ at $4^{\circ} \mathrm{C}$ and washed once using $100 \mu \mathrm{l} 70 \%$ ethanol and centrifuged for $5 \mathrm{~min}, 14000 \mathrm{~g}$ at $4^{\circ} \mathrm{C}$. Ethanol was removed and the pellet was dried at $37^{\circ} \mathrm{C}$. DNA was then solubilized in $16.5 \mu$ nuclease free water. In vitro transcription was performed in a reaction mixture containing $5 \mu \mathrm{l} 10 \mathrm{x}$ transcription reaction

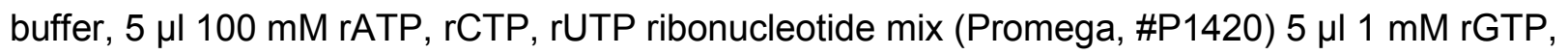

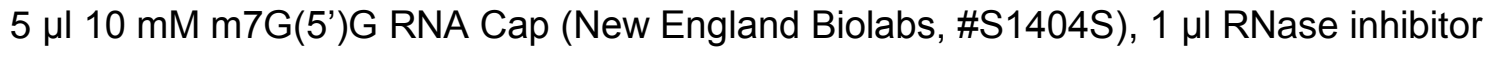
(Promega, \#P1420), and SP6 RNA polymerase (Promega, \#P1420) and incubated at $37^{\circ} \mathrm{C}$ for 30 minutes. $1.25 \mu \mathrm{l}$ of $10 \mathrm{mM}$ rGTP was added and incubated for additional 1 hour at $37^{\circ} \mathrm{C}$. To avoid degradation of the RNA, $0.5 \mu$ l of the RNase inhibitor and $2.5 \mu \mathrm{RQ}$ DNase1 (Promega, \#P1420) were added followed by incubation for 15 minutes at $37^{\circ} \mathrm{C}$. Free nucleotides and digested DNA were removed using Illustra ProbeQuant G-50 Microcolumns. Synthesized RNAs were purified by phenol:chloroform extraction and ethanol precipitation as above and stored at $80^{\circ} \mathrm{C}$.

\section{Xenopus laevis in vitro fertilization and embryo culture}

Adult Xenopus laevis were obtained from Nasco (Fort Atkinson, WI) and housed at Rutgers University-Newark and used in accordance with institutional guidelines and the approval of the local Institutional Animal Care and Use Committee. Female frogs were injected subcutaneously with a priming dose of human chorionic gonadotropin (hCG) $50 \mathrm{U}(2 \mathrm{U} / \mu \mathrm{l})$ (MP Biomedicals, \#198591) in the dorsal lymph sac 7-10 days preceding induction of ovulation. Females were 
induced to ovulate by injection of $500 \mathrm{U}$ human chorionic gonadotropin and incubated at $15^{\circ} \mathrm{C}$ until ovulation commenced, typically 12 hours later. Females were manually 'squeezed' to yield eggs.

To achieve synchronous fertilization, $\sim 1 \mathrm{~mm}$ thick fragment of the testis was macerated and further homogenized in $1 \mathrm{ml}$ 1x Modified Barth's Saline (1x MBS: $88 \mathrm{mM} \mathrm{NaCl}, 1.0 \mathrm{mM} \mathrm{KCl,} 2.4$ $\mathrm{mM} \mathrm{NaHCO}_{3}, 15.0 \mathrm{mM}$ HEPES (pH 7.6), 0.3 mM Ca(NO$)_{2}-4 \mathrm{H}_{2} \mathrm{O}, 0.41 \mathrm{mM} \mathrm{CaCl}_{2}-2 \mathrm{H}_{2} \mathrm{O}, 0.82$ $\mathrm{mM} \mathrm{MgSO}_{4}$ ). Eggs were thoroughly mixed with the sperm suspension and allowed to sit for 3 minutes before flooding the Petri dish with deionized water. After 20 mins fertilized eggs were dejellied by gently swirling (3-5 minutes) in a $2 \%$ cysteine hydrochloride (Amresco, \#200-157-7), $\mathrm{pH} 7.8$ solution in $0.1 \times$ MBS. Dejellied zygotes were thoroughly rinsed with deionized water followed by $0.1 \times \mathrm{MBS}$. Zygotes were then cultured in $0.1 \times \mathrm{MBS}$ at $15^{\circ} \mathrm{C}$ until they were ready to be used for experiments.

\section{Embryo microinjections}

To target ectodermal (animal cap) tissue, Xenopus zygotes were microinjected at one-cell stage

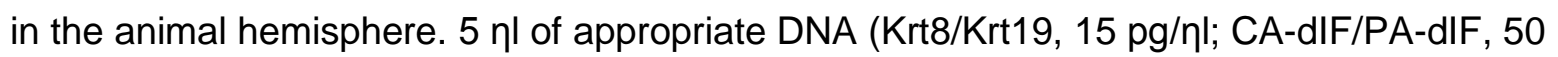
$\mathrm{pg} / \mathrm{hl}$ ) or RNA (Krt8/Krt19, $100 \mathrm{pg} / \mathrm{\eta l}$; CA-dIF/PA-dIF, 20-50 pg/nl) diluted in deionized water was pressure injected using a Narishige IM-300 microinjection apparatus. Microinjection needles were fabricated from borosilicate glass capillaries (Drummond, \#1000 0010) using a P-30 vertical micropipette needle puller (Sutter Instrument, CA) at settings 760 units for heat and 400 units for pull. Needles were calibrated to the desired injection pressure (20-30 PSI) and time (100-200 ms) settings to dispense $5 \mathrm{\eta l}$ of injection volume. During injections and 20 minutes post injection, the embryos were kept in 3\% Ficoll (Amresco, \#E965-504). Embryos were rinsed thoroughly and transferred to $0.1 \times$ MBS and allowed to develop to the gastrulation stage by 
maintaining in a $15^{\circ} \mathrm{C}$ incubator. To avoid unintended photoactivation, embryos were maintained in the dark and all experimental steps were performed under red light only.

\section{Preparation of ectodermal tissue (animal caps) explants}

Basic animal cap explants were prepared from Xenopus embryos at gastrulae stage 11-11.5 in a $100 \mathrm{~mm}$ dish containing $0.1 \times$ MBS. First, the embryos were devitellinized from the vegetal side using forceps to avoid damaging the animal cap. Next, the animal caps were excised using the eyebrow knife. The blastocoel side of the animal hemisphere was exposed from the vegetal side and then the region of the animal cap with fluorescence was identified and cut. To obtain the animal cap region expressing the injected proteins, the sides of the explants were shaved to appropriate size. The explanted animal caps were then transferred to a $35 \mathrm{~mm}$ dish coated with fibronectin $\left(1.4 \mathrm{\mu g} / \mathrm{cm}^{2}\right)$ containing $0.5 x \mathrm{MBS}$ using a Pasteur pipette. Explants were positioned with the deep layer facing the bottom of the chamber. After arranging the explant on the substrate, a small fragment of the cover slip supported by silicone grease at the four corners was used to compress the explant gently with forceps. Ectodermal explants were then allowed to attach onto the substrate for about 30 minutes before image acquisition.

\section{Developmental phenotypes}

Synchronously fertilized embryos were harvested for analysis at the desired developmental stage according to the external morphology as described by (Nieuwkoop and Faber, 1994). Embryos were kept at a density of maximum 50 embryos per $35 \mathrm{~mm}$ dish and $0.1 \mathrm{x}$ MBS was replaced daily.

\section{Cell culture and transfection}

Madin-Darby canine kidney epithelial cells and HEK293T cells were obtained from ATCC (CCL34 and CRL-3216, respectively). Cells were maintained in growth medium consisting of 
Dulbecco's modified Eagle's medium (DMEM) (Gibco, \#31053028) containing 10\% Fetal bovine serum (FBS) (Gibco, \#10438026), 1\% Penicillin- Streptomycin (Gibco, \#P0781), 1\% Glutamax (Gibco, \#35050-061), $26.18 \mathrm{mM} \mathrm{NaHCO}_{3}$ and filtered sterilize using $0.2 \mu \mathrm{m}$ vacuum filter. Cells were grown at $37^{\circ} \mathrm{C}$ with $5 \% \mathrm{CO}_{2}$ in a humidified tissue culture incubator. Cells were not used beyond passage 20 and were cultured from frozen stock.

HEK293T and MDCK cells expressing mCherry CA-dIF/PA-dIF were generated by transfection of the $\mathrm{pCS}^{+}$mCherry-PA/CA-dIF construct using BioT plasmid transfection reagent (Bioland Scientific, B01-00) or Lipofectamine 3000 (Invitrogen, Life Technologies), respectively, according to manufacturer's guidelines. Briefly, cells were seeded onto $35 \mathrm{~mm}$ dishes to achieve $70-80 \%$ confluency at the time of transfection. Next, $10 \mu \mathrm{l}$ of Opti-MEM reagent was incubated with $0.3 \mu \mathrm{l}$ of Lipofectamine, $0.2 \mu \mathrm{l}$ of P3000 and 0.1-0.2 $\mu \mathrm{g}$ of DNA for 15 minutes and then the DNA-lipid complexes were added on to the seeded cells. For $35 \mathrm{~mm}$ dishes, $150 \mu \mathrm{l}$ of Opti-MEM reagent was incubated with $10 \mu \mathrm{l}$ of Lipofectamine, $7.5 \mu \mathrm{l}$ of P3000 and 1-1.5 $\mu \mathrm{g}$ of DNA for 15 minutes and then the DNA-lipid complexes were added on to the seeded cells. Cells were incubated for 6 hours at $37^{\circ} \mathrm{C}$ before exchanging for fresh cell culture medium. Cells transfected with PA-dIF constructs were handled in dark or under red light to avoid unintended activation.

\section{Xenopus laevis embryo lysis and biochemistry}

Embryos at stage 10.5-11 were sorted for eGFP or mCherry fluorescence to ensure expression of proteins from the injected mRNA. Fluorescence-positive embryos were homogenized on ice with pre-chilled extraction buffer (100 mM NaCl, 50 mM Tris- $\mathrm{HCl}(\mathrm{pH} 7.5), 1 \%$ Triton X-100, 1 mM phenylmethylsulfonofluoride (PMSF), $10 \mathrm{mg} / \mathrm{ml}$ sodium $\beta$-glycerophosphate, $10 \mathrm{mM}$ sodium fluoride, $1 \mathrm{mM}$ sodium orthovanadate, $0.2 \mathrm{mM} \mathrm{H}_{2} \mathrm{O}_{2}$, $3 \mathrm{mM}$ sodium pyrophosphate, with mammalian protease inhibitor cocktail (Sigma, \#P2714)). The embryo slurry was incubated on 
ice for 15 mins followed by centrifugation for 10 minutes at $14,000 \mathrm{~g}$ at $4^{\circ} \mathrm{C}$. To clarify the lysate, the yolk from the upper phase was aspirated. If a sequential aspiration was necessary the supernatant was centrifuged again with the same conditions. If the lysate was not used immediately, samples were frozen at $-80^{\circ} \mathrm{C}$, aliquoted for SDS/PAGE, and/or immunoprecipitated.

\section{Co-immunoprecipitation}

Immunoprecipitations were performed with RFP-Trap_MA (Chromotek, Germany, \#rtma20) using $100 \mu \mathrm{l}$ total lysates extracted from uninjected embryos or embryos injected with either

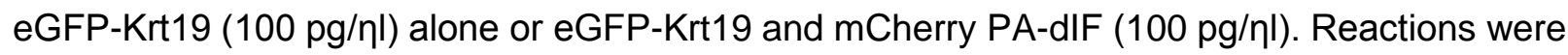
incubated for 1 hour at $4^{\circ} \mathrm{C}$, beads were then magnetically separated and further washed 3 times with lysis buffer. Immunocomplexes were dissociated from beads by $40 \mu$ l of 2x Laemmli buffer with $5 \% \beta$-mercaptoethanol and boiling for 10 minutes. Samples were then separated by SDS-PAGE. Polyacrylamide gels of $12 \%$ or $14 \%$ concentration were prepared by mixing appropriate volumes of $1.5 \mathrm{M}$ Tris- $\mathrm{HCl} \mathrm{pH} 8.8,30 \%$ Acrylamide-Bis acrylamide (Biorad), $10 \%$ SDS, 10\% ammonium persulfate (Sigma), 0.02\% TEMED (VWR). A 4\% stacking gel was made by mixing appropriate volumes of $0.5 \mathrm{M}$ Tris- $\mathrm{HCl} \mathrm{pH} 6.8,30 \%$ acrylamide (Biorad), $10 \%$ SDS, 10\% ammonium persulfate (Amresco), 0.02\% TEMED (VWR). Gels were loaded with protein samples and run at $80-100 \mathrm{~V}$. After separation, proteins were stained with Sypro Red dye (Invitrogen, S12000).

\section{LC/MS-MS Proteomic Analysis}

Prior to staining with Sypro Red dye, SDS-PAGE gels were incubated twice in fixative solution consisting of $50 \%$ methanol and $7 \%$ glacial acetic acid for 30 minutes per incubation. After decanting the second fixative solution, the gel was placed in a fresh dish and incubated in $60 \mathrm{ml}$ 
of Sypro Red dye overnight. The staining solution was decanted and the gel was incubated in a wash solution of $10 \%$ methanol and $7 \%$ glacial acetic acid for 30 minutes. Afterwards, the gel was washed three times in $100 \mathrm{ml}$ of commercial ultrapure water before gel imaging and further preparation for LC/MS-MS. All incubations and washes were performed at room temperature on a flat rotator.

LC/MS-MS was performed by the Center for Advanced Proteomics Research (CAPR) at the Rutgers New Jersey Medical School. Sypro Red-labeled SDS-PAGE gel sections were excised at the facility and in-gel trypsin digestion was performed. The resulting peptides were C18 desalted and analyzed by LC/MS-MS on the Q Exactive instrument. The MS/MS spectra were searched against the NCBI Xenopus laevis database using Sequest search engines on the Proteome Discoverer (V2.1) platform. The protein false discovery rate (FDR) is less than $1 \%$. The comparison of identified proteins and their relative quantitation was calculated based on the spectra counting method and compared for consistency across two independent experiments. In addition to the $1 \%$ FDR, for inclusion in the final data table shown in Figure 3, proteins had to meet all of the following criteria: molecular weight between $40-75 \mathrm{kDa}, 3$ or more unique peptides in each single-run analysis, spectral count in the CA-dIF sample of 10 or more, and a ratio of enrichment in the CA-dIF sample of 1.5 or greater.

\section{Indirect Immunofluorescence}

MDCK or HEK293T cells were seeded on $35 \mathrm{~mm}$ glass bottom dishes (MatTek). Cells were fixed in ice cold $100 \%$ methanol for $10-15$ mins on ice and then washed 3 times with PBS. Cells were permeabilized with $0.25 \%$ Triton X-100 diluted in PBS and rinsed 3 times with PBS. Cells were blocked for $1 \mathrm{hr}$ at $37^{\circ} \mathrm{C}$ with $10 \%$ goat serum, $1 \% \mathrm{BSA}$ and $0.1 \%$ Triton $\mathrm{X}-100$ diluted in PBS, following which samples were incubated with primary antibodies diluted in blocking buffer for 30 mins at $37^{\circ} \mathrm{C}$ or overnight at $4^{\circ} \mathrm{C}$. Samples were then thoroughly washed with PBS and 
then incubated with secondary antibodies, Hoechst 34580 (1:10,000; Sigma Aldrich, \#63493) for 30 mins at $37^{\circ} \mathrm{C}$, rinsed again 3 times with PBS.

Pan-cytokeratin (1:100, C2562, Sigma-Aldrich) primary antibody was used for immunofluorescence. Secondary antibodies used were species-specific AlexaFluor-lgG conjugates (1:1000) (Life Technologies). mCherry fluorescence was preserved through fixation and labeling.

\section{Confocal microscopy and image analysis}

Confocal images were acquired with Zeiss Cell Observer SD using Zen software (Zeiss) equipped with a Plan-Apochromat 63X/1.4 oil immersion objective, 1.0 or 1.6 Optovar. Z-stacks with a step size of $0.25-0.30 \mu \mathrm{m}$ were acquired for each field. For optimal images, $\mathrm{z}$-stack maximum intensity projections were processed from z-stacks collected through the entire cell and only linear adjustments were made to their brightness and contrast.

Linescan measurements of fluorescence were conducted using the linescan tool in the profile tab of the Zen 2.3 lite software application. Measurements were taken in a region of cytoplasmic volume for a length of $15 \mu \mathrm{m}$. Intensities were normalized to the intensity value at the beginning of the linescan in order to view intensity fluctuation.

For photoactivation studies, embryos were co-injected with mCherry PA-dIF or mCherry CA-dIF (DNA, $50 \mathrm{pg} / \mathrm{\eta l})$ and eGFP-Krt8 (DNA, $15 \mathrm{pg} / \mathrm{\eta l})$. Ectodermal explants were prepared as described above. Because we observed that high expression of PA-dIF may disrupt keratin networks even when maintained in dark conditions, cells with apparently normal IF networks and general cell morphology and having moderate expression of mCherry PA-dIF were selected 
for photoactivation. Cells were imaged with a Zeiss Cell Observer SD confocal microscope using a Plan-Apochromat 63X/1.4 oil immersion objective, 1.0 Optovar and a DirectFRAP module. To induce PA-dIF activation, a $458 \mathrm{~nm}$ laser was focused into a small circular area (diameter $10 \mu \mathrm{m}$ ) for 30 seconds with $100 \%$ laser intensity. This combination of settings yielded an $8 \mu \mathrm{W}$ blue light exposure. Images were acquired every 15 secs for 1 min before and between irradiation periods, and then for 5-10 minutes following the last irradiation.

\section{Photoactivation of PA-dIF in embryos}

For blue light stimulation of whole embryos, $35 \mathrm{~mm}$ dishes containing either control or mCherry PA-dIF (CA-dIF/PA-dIF, 20-50 pg/nl) injected embryos were placed underneath a home-built (50X40 mm) LED array. Briefly, an LED array was constructed with 56 blue $5 \mathrm{~mm}$ LEDs (470 $\mathrm{nm}, 7065$ millicandelas each max output) with a mean $100 \mu \mathrm{W}$ measured output. The LEDs were powered through a $40 \mathrm{~V}$ power supply with a potentiometer for intensity control. Following microinjection of mCherry PA-dIF, the embryos were illuminated with oscillating pulses every sec with a minimum $53 \mu \mathrm{W}$ and maximum of $154 \mu \mathrm{W}$ intensity or maintained in the dark, until the embryos reached desired stages. Embryos were fixed in $4 \%$ formaldehyde at desired timepoints and analyzed for morphology.

\section{$\underline{\text { Results }}$}

\section{Rational design of a photoactivatable disruptor of keratin intermediate filaments}

The highly conserved C-terminal portion of the $\alpha$-helical rod domain, 2B2, is known to be critical for the dimerization of intermediate filaments (Fig. 1A) (Strelkov et al., 2002). Previous work has shown that as few as 20 amino acids from this region is sufficient to disrupt keratin 
assembly in vitro (Hatzfeld and Weber, 1992; Steinert et al., 1993b, 1993a). Dimerization of these mimetic peptides with their endogenous keratin partner prevents further assembly into mature filaments, resulting in a combination of intermediate filament precursors and more general filament disruption and aberrant aggregation. Similarly, peptides resembling the 2B2 region of intermediate filaments efficiently disrupt intermediate filaments in vivo (Helfand et al., 2011).

We sought to create a fluorescently-traceable photoactivatable fusion protein that contained 2B2 and which could be acutely 'activated' to disrupt intermediate filaments with subcellular spatial resolution. Based on data from Hatzfeld and Weber (Hatzfeld and Weber, 1992), we used a near-minimum number of amino acids from the C-terminal part of $2 \mathrm{~B} 2$ derived from Xenopus Krt8 as the template for our inhibitory peptide. This amino acid sequence is highly conserved across intermediate filament proteins (Fig. 1B) and species (Fig. S1). 2B2 was fused to the Ja helical region of the LOV-J $\alpha$ domain from $A$. sativa phototropin-1 (Fig. 1C, Fig. S2). Several strategies noted by other laboratories were used in our design in order to maximize caging while allowing $2 \mathrm{~B} 2$ to be available for binding upon photoirradiation. Tighter caging was suggested to be enhanced by minimizing peptide sequence that extends beyond the LOV-J $\alpha$ interface. Both J $\alpha$ and 2B2 are amphipathic $\alpha$-helices (Fig. 1D). The hydrophobic side of the Ja helix folds against the adjacent globular LOV domain (Harper et al., 2003; Möglich et al., 2009). In the case of $2 B 2$, coiled-coil formation of the intermediate filament dimer is facilitated by this amphipathic property. In order to promote $\alpha$-helix formation and folding of the fusion helix against the globular LOV region, we performed a series of in silico analyses. Lungu et al. suggested that embedding the peptide within the Ja helix yields improved caging potential but with the caveat that accessibility of the peptide may be limited, even in the lit state (Lungu et al., 2012). In an effort to balance this cost-benefit, we fused the 22 amino acid 2B2 sequence directly to the end of $\mathrm{J} \alpha$. Fusion of $2 \mathrm{~B} 2$ to $\mathrm{J} \alpha$ is predicted to create a nearly contiguous $\alpha$-helical 
domain (Fig. S3A,B). Analysis of the $\alpha$-helix formed by J $\alpha$ and 2B2 showed that the amphipathic nature of the helix was predicted to be preserved in a fusion construct (Fig. 1D). A continuous $\alpha-$ helix with a similar hydrophobic moment to either Ja or 2B2 alone is expected. Predictive 3D modeling of sequences encoding LOV-J $\alpha$, LOV-J $\alpha-2 B 2$, and mCherry-LOV-J $\alpha-2 B 2$ were performed using Phyre2 (Kelley et al., 2015). Modeling of LOV-J $\alpha$ closely resembles other predicted and actual X-ray crystallography- and solution NMR spectroscopy-based structures of the domain (Fig. S4A) (Harper et al., 2003; Wu et al., 2009; Lungu et al., 2012). The addition of the intermediate filament 2B2 domain extended the Ja helix (Fig. S4B). Interestingly the addition of a mCherry fluorophore to the fusion protein generated a loop and turn in the J $\alpha$-2B2 helix (Fig. S4C). In either case, the 2B2 domain is predicted to be helical in structure and associate with the globular LOV domain. An additional construct containing a mutation within the J $\alpha$ domain of I379E yielded a 'lit-state' variant (Fig. 1E) that cannot fold properly due to steric hindrance of the LOV-Ja interaction (Fig. S4D) (Harper et al., 2004; Wu et al., 2009; Zimmerman et al., 2016). These strategies yielded two constructs: 1) a PhotoActivatable

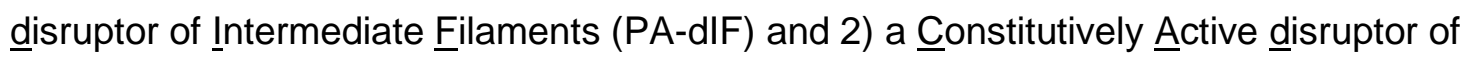
Intermediate Filaments (CA-dIF).

\section{CA-dIF perturbs intermediate filament network and nuclear morphology}

We first sought to test these constructs for their caging ability and whether the 2B2 sequence would still remain functional after having been fused with the Ja. Although the sequence of 2B2 used originates from frog Krt8, the high homology suggested that this sequence should disrupt keratin intermediate filaments across species and cell types (Fig. S1). We transfected HEK293T and MDCK cells with either CA-dIF or PA-dIF to test the ability of the constructs to disrupt IFs and the ability of the LOV-Ja domain to effectively mask the 2B2 peptide. Transfected cells were maintained in typical incubator conditions in the dark where PA- 
dIF would not be activated. HEK293T cells transfected with PA-dIF and maintained in the dark exhibited normal spindly keratin networks typical for this cell line (compare untransfected mCherry- cells to transfected mCherry+ cells, Fig. 2A). Nuclei in these cells were similarly robust and oval in shape. In contrast, HEK293T cells expressing CA-dIF showed a punctate perinuclear aggregation of the keratin network (Fig. 2B). Nuclei in CA-dIF cells were often lobulated and dysmorphic.

MDCK cells originated from canine kidney epithelia and are enriched with a diverse number of keratin intermediate filament proteins. Normal untransfected MDCK cells have a wellspread keratin network distribution and oval nuclei (Fig. 2C). No observable differences were noted between untransfected MDCK cells and mCherry PA-dIF cells (Fig. 2D). MDCK cells transfected with CA-dIF showed perinuclear clustering of the keratin network, although not to the same degree as HEK293T cells (Fig. 2E). Filaments were shorter and less distinct, which produced less intensity fluctuation by line-scan analyses of keratin labelling in the cytoplasm (Fig. 2F,G). Like HEK293T cells, MDCK cells also showed some nuclear morphology changes, but again, these were not as severe. Altogether, these data show the capacity of CA-dlF to disrupt keratin intermediate filaments in multiple cell and species types. In addition, these findings provide evidence that suggests PA-dIF is effectively caged when maintained in the dark.

\section{Photoactivation of PA-dIF disrupts keratin intermediate filaments}

While peptides of truncated 2B2 region of intermediate filaments have been demonstrated to disrupt intermediate filaments in vitro, these peptides have not been widely used to perturb intermediate filaments in cells and, to our knowledge, no studies to date have used this peptide in vivo in the whole organism. Previously, peptide mimetics of the 2B2 domain have been used in in vitro assays of intermediate filament assembly and in a few studies microinjected into living cells (Hatzfeld and Weber, 1992; Steinert et al., 1993a; Strelkov et al., 
2002; Helfand et al., 2011). In principle, by caging this peptide with the photoactivatable LOV-Ja module, our developed tool could be light-activated in living cells to disrupt intermediate filaments at the subcellular spatial scale.

Early Xenopus laevis embryos provide a useful model organism in which to investigate the developmental and cell biological roles of intermediate filaments. During early embryonic development, expression of intermediate filament proteins is limited to Krt8, Krt18, and Krt19 into the early morphogenetic events of gastrulation with vimentin emerging in the ectodermal layers toward late gastrulation. The Krt8/18/19 keratin complement is present in all tissues of the embryo from egg through gastrula. Fluorescently-tagged Krt8 or Krt19 readily incorporates into intermediate filament networks of the Xenopus embryo and can be used to track the keratin network in living tissue (Weber et al., 2012; Mariani et al., 2018). To investigate the ability of dIF constructs to disrupt keratin networks in an in vivo model system, we co-injected mRNA encoding PA-dIF or CA-dIF with either eGFP-Krt8 or eGFP-Krt19 into the animal cap of Xenopus embryos. Ectodermal animal cap explants were prepared at gastrulation and keratin intermediate filaments were imaged in live cells of the deep cell layers. Keratin intermediate filament networks were distributed throughout the cell body of ectodermal cells (Fig. 3A), similar to that previously described in unpolarized mesendoderm cells (Weber et al., 2012). Likewise, coalescence of keratin filaments was seen occasionally near cell-cell contacts.

We first co-expressed mCherry-CA-dIF and eGFP-Krt8 to examine whether the filamentous keratin network was disrupted when the open-state fusion construct was expressed (Fig. 3B). Keratin filaments formed punctate aggregates throughout mCherry positive cells, even at low expression levels. To confirm the molecular target of our dIF constructs when expressed in vivo, we immunoprecipitated CA-dIF from injected Xenopus gastrula and looked for enrichment of proteins in mCherry-CA-dIF samples (Fig. 3C). Protein bands were enriched in the molecular weight range of $37-75 \mathrm{kD}$. These bands were isolated and liquid chromatographytandem mass spectroscopy analyses were performed to identify endogenous proteins that were 
binding to CA-dIF. Keratin 18 isoforms originating from both $X$. laevis alleles predominated in terms of both unique peptides identified, spectral counts, and were identified as the top target proteins of our construct with few other proteins enriched (Fig. 3D).

To test the ability of PA-dIF to disrupt intermediate filaments, cells expressing PA-dIF were photoirradiated with $458 \mathrm{~nm}$ light for a period of 30 seconds while performing time-lapse imaging. No change to the intermediate filament network was observed in cells expressing eGFP-Krt8 and mCherry (Fig. 4A). In cells expressing PA-dIF, exposure to blue light induced the rapid collapse of keratin filaments specifically in the immediate vicinity of illumination (Fig. 4B-D). While total collapse of the keratin filaments was isolated to the region of photoirradiation, this localized perturbation had widespread consequences for the intermediate filament network beyond the local effect, causing filaments nearby to appear more tortuous rather than taut. However, only in the area where illumination occurred did filaments completely collapse and aggregate. To further explore the capability of PA-dIF to disrupt the intermediate filament network in an acute manner, we performed repeated illuminations of a single cell where we systematically targeted filaments that remained until the entire intermediate filament network was collapsed. Repeated photoirradiation was able to acutely disrupt the entire intermediate filament network within a cell in a period of less than 10 minutes (Fig. 4D).

\section{Keratin filaments are necessary for normal Xenopus embryo development}

Having demonstrated the ability of PA-dIF to disrupt the intermediate filament network in individual cells, we next sought to examine the consequences of intermediate filament disruption on early development. Xenopus embryos were injected with mRNA encoding eGFPKrt19 and mCherry alone, CA-dIF, or PA-dIF and grown to tailbud stages in the dark or in the presence of blue (458 nm) light. Uninjected and mCherry-injected embryos developed normally

(Fig. 5, uninjected). In contrast, CA-dIF injected embryos exhibited perturbations in the ectoderm that became apparent during gastrulation (Fig. 5A), a time in which the embryo 
undergoes major morphogenetic changes as well as increased zygotic protein expression.

Extruding yolk plugs could be seen in CA-dIF embryos as they progressed into neurulation (Fig.

5B). By early tailbud and continuing through late tailbud stages, CA-dIF embryos had an open

dorsal region, likely originating from the failed blastopore closure (Fig. 5C,D). In tadpoles, this

open dorsal aspect persisted in CA-dIF injected embryos (Fig. 5E). Additionally, CA-dIF

tadpoles often had underdeveloped head structures, poor midline separation, a bifurcated

shortened tail, and a ventral edema (Fig. 5E). These abnormalities were characteristic of CA-

dIF/eGFP-Krt19 expressing embryos, but not wildtype or mCherry/eGFP-Krt19 expressing embryos (Fig. 5F).

Xenopus embryos injected with 100-175 pg mRNA encoding PA-dIF and maintained in the dark appeared largely like their wildtype and mCherry injected counterparts (Fig. 6A-C). Developmental defects paralleling the CA-dIF phenotypes were induced when PA-dIF embryos were grown under blue light conditions (Fig. 6B,C,F). Injection of greater amounts of PA-dIF mRNA (250-500 pg) resulted in developmental abnormalities irrespective of blue light exposure that were only mildly enhanced by blue light exposure (Fig. 6D-F). Nonetheless, the developmental perturbations due to photoactivation of PA-dIF and its expression at higher levels were consistent with those observed by CA-dIF expression. Altogether, these data show an important role for intermediate filaments during development of the ectoderm in the early embryo.

\section{Discussion}

We describe herein the generation of PA-dIF, a novel genetically encoded, photoactivatable peptide that can be used to rapidly disrupt intermediate filaments with subcellular spatial resolution. Notably the disruption of the intermediate filaments described is induced without introduction of mutations to intermediate filaments or manipulation of intermediate filament expression levels. We accomplished the disruption by introducing 
expression of a short peptide that can be made available for disruption through photomanipulation and titered as necessary. Through this approach, these constructs can be used to target intermediate filaments at a subcellular scale or more broadly disrupt in cells and tissues where expressed and photoactivated. In addition, we have used the classic developmental biology system of Xenopus and the emergence of developmental phenotypes to test this novel photoactivatable biomolecular tool.

Deciphering the role of keratins in early embryonic development has thus far been difficult, due to functional redundancy and complexity within the family, generation of exogastrulation or embryonic lethal phenotypes in intermediate filament knockout and knockdown animal models, and a lack of specific polymerization inhibitors characterized for intermediate filaments. In vitro, 2B2 peptide of vimentin inhibits intermediate filament assembly (Strelkov et al., 2002). This disassembly resulted in formation of unit length filament-like structures. Similarly, synthetic 2B2 peptides based on keratins as a template also interfered with both intermediate filament assembly and disrupted pre-assembled filaments (Hatzfeld and Weber, 1992). In vivo, microinjection of 2B2 peptide in fibroblasts causes disruption of vimentin network into short filaments and ULF-like structures (Helfand et al., 2011). In our study using a sequence similar in length to Hatzfeld and Weber (Hatzfeld and Weber, 1992), we observe primarily disruption, collapse and aggregation of the filaments at the site of PA-dIF activation; however, the details of this perturbation and nature of the effects on polymerization remain to be determined. As expected, CA-dIF yields a more widespread disruption and the intermediate filaments appear sparser, less well-defined and often punctate.

Questions remain as to how exactly PA-dIF is incorporating and disrupting the existing filamentous network. We observed that disruption of the intermediate filament network remains sharply within the region of photoactivation. It is apparent that this tool is acutely activated by exposure to blue light resulting in disruption of intermediate filaments. Expression of PA-dIF needs to be tightly regulated and we found that titration of PA-dIF to appropriate expression 
levels was essential to maintaining dynamic light responsiveness. High expression levels of PAdIF was sufficient to cause disruption even in dark conditions, similar to CA-dIF. In view of this, improving caging and/or expressing PA-dIF under a titratable expression system will be necessary for greater utility across other cell systems. We have yet to explore whether mutations in LOV-Ja may enhance caging (Zimmerman et al., 2016), but the current photoactivatable construct is sufficient to prevent dIF disruption of the keratin network in the dark and under moderate expression. We also found that CA-dlF can be used to disrupt keratin intermediate filaments simply by expression in cells of multiple species and types. Future work will be aimed at determining the cell biological consequences of intermediate filament perturbation using these tools.

Given the highly conserved sequence homology, we expect that dIF constructs may also disrupt multiple intermediate filament networks. In our LC-MS/MS analyses, vimentin and nuclear lamins were associated with CA-dIF; however, they were found at a much lesser extent and did not meet our stringent proteomics criteria. We did observe notably lobular nuclei, particularly in HEK293T cells transfected with CA-dIF. This nuclear morphology may have resulted from either direct perturbation of nuclear lamins or, more likely, indirect effects on the nucleus that resulted as a consequence of keratin disruption in the cytoplasm. While we cannot determine that the effects of dIF are due exclusively to disruption of the keratin network, this possible affinity of dIF to multiple intermediate filament proteins suggests that the tool may broadly be used to disrupt intermediate filament networks. In this respect, dIF constructs are among a very limited set of tools that can be used for the interrogation of intermediate filaments (Zwerger et al., 2015; Ridge et al., 2016). Nonetheless, Krt18 appeared to be the primary target for our dIF constructs in the early Xenopus embryo. Interestingly, we did not find Krt19 particularly enriched in CA-dIF expressing samples even though recent work from our laboratory indicates an important role for 14-3-3 binding to Krt19 for intermediate filament recruitment to cell-cell adhesions (Mariani et al., 2018). Conversely, in that study, we did not find Krt18 
associated with 14-3-3. We do not yet know why Krt19 was not associated with our dIF constructs but tentatively speculate that the association of 14-3-3 with Krt19 and/or subcellular compartmentalization may diminish dIF-Krt19 interaction.

Keratin filaments have important roles in normal morphogenesis during Xenopus embryonic development as revealed by these new biomolecular tools: PA-dIF and CA-dIF. In prior work, we have inhibited overall keratin expression by injection of embryos with morpholinos, which block translation of zygotic protein. Krt8 morpholino injected embryos exhibited an exogastrulation phenotype characterized by extrusion of the vegetal endoderm out the blastopore (Weber et al., 2012). The phenotypes elicited by morpholino knockdown were similar to those observed in embryos injected with antibodies against keratins (Klymkowsky et al., 1992) or oligonucleotide-induced knockdown of keratin expression (Heasman et al., 1992; Torpey et al., 1992). Here, we describe a third method of disrupting intermediate filaments. Unique to the usage of dIF constructs versus prior knockdown methods is that the present tool distinguishes the role of intermediate filaments as a cytoskeletal network from intermediate filament proteins more generally. In addition, expression of the dIF constructs is more selective for particular tissues because expression is limited to the region proximal to injection (Colman and Drummond, 1986) whereas morpholinos readily diffuse throughout the Xenopus embryo (Nutt et al., 2001). In our studies here, we limited expression to presumptive ectodermal tissues through targeted injection of the animal cap. Morphogenetic processes associated with the ectodermal tissue were indeed the main manifestation of the induced defects. Although involution and blastopore constriction have been claimed to be directed primarily by morphogenetic movements in the vegetal and marginal zones (Keller et al., 2003), we induced incomplete yolk plug closure through perturbation of keratins in the ectoderm. Previously it has been suggested that ectodermal movements are an initiating and essential component of subsequent gastrulation movements (Beloussov et al., 2006). Indeed, many perturbations that disrupt ectodermal movements (i.e. epiboly) and extracellular matrix assembly on the blastocoel 
roof also frequently result in exogastrulation (Rozario et al., 2009; Eagleson et al., 2015). Our data provided here are further experimental evidence that ectodermal movements on their own are an important contributing factor to the overall movements leading to complete blastopore constriction.

Future experiments will determine the contribution of intermediate filaments to morphogenetic movements in other tissues. Furthermore, we now have the capability to examine the role of intermediate filaments in stages beyond gastrulation by simply waiting to expose embryos to blue light until developmental stages of choice. With the flexibility of both spatial and temporal disruption using PA-dIF, the utility of PA-dIF for examining functional developmental roles of intermediate filaments is limitless.

\section{Acknowledgements}

We would like to thank the members of the Weber laboratory for helpful discussions and advice. Special thanks to Abid Haque of the Weber lab who constructed the blue light box used for the photoactivation of whole embryos. This research was supported by a Rutgers UniversityNewark Dissertation Fellowship to R.S-S. and grant HD084254 from the Eunice Kennedy Shriver National Institute of Child Health and Human Development to G.F.W. The mass spectrometry data were obtained from an Orbitrap mass spectrometer funded in part by an NIH grant NS046593, for the support of the Rutgers Mass Spectrometry Center for Integrative Neuroscience Research.

\section{$\underline{\text { References }}$}

Beloussov, L. V., Luchinskaya, N. N., Ermakov, A. S., and Glagoleva, N. S. (2006). Gastrulation in amphibian embryos, regarded as a succession of biomechanical feedback events. Int. J. Dev. Biol. 50, 113-122. 
Block, J., Schroeder, V., Pawelzyk, P., Willenbacher, N., and Köster, S. (2015). Physical properties of cytoplasmic intermediate filaments. Biochim. Biophys. Acta - Mol. Cell Res. 1853, 3053-3064.

Colman, A., and Drummond, D. (1986). The stability and movement of mRNA in Xenopus oocytes and embryos. J. Embryol. Exp. Morphol. 97, 197-209.

Coulombe, P. A., and Fuchs, E. (1990). Elucidating the early stages of keratin filament assembly. J. Cell Biol. 111, 153-169.

Dodemont, H., and Riemer, D. (1990). Structure of an invertebrate gene encoding cytoplasmic intermediate filament (IF) proteins : implications for the origin and the diversification of IF proteins. EMBO J. 9, 4083-4094.

Döring, V., and Stick, R. (1990). Gene structure of nuclear lamin LIII of Xenopus laevis; a model for the evolution of IF proteins from a lamin-like ancestor. EMBO J. 9, 4073-4081. Eagleson, G., Pfister, K., Knowlton, A. L., Skoglund, P., Keller, R., and Stukenberg, P. T. (2015). Kif2a depletion generates chromosome segregation and pole coalescence defects in animal caps and inhibits gastrulation of the Xenopus embryo. Mol. Biol. Cell 26, 924-937. Franke, W., Schiller, D., Schmid, R., and Engelbrecht, I. (1981). Diversity of cytokeratins. J. Mol. Biol. 153, 933-959.

Franz, J. K., Gall, L., Williams, M. A., Picheral, B., and Franke, W. W. (1983). Intermediate-size filaments in a germ cell: Expression of cytokeratins in oocytes and eggs of the frog Xenopus. Proc. Natl. Acad. Sci. U. S. A. 80, 6254-6258.

Gautier, R., Douguet, D., Antonny, B., and Drin, G. (2008). HELIQUEST: a web server to screen sequences with specific -helical properties. Bioinformatics 24, 2101-2102.

Harper, S. M., Neil, L. C., Day, I. J., Hore, P. J., and Gardner, K. H. (2004). Conformational Changes in a Photosensory LOV Domain Monitored by Time-Resolved NMR Spectroscopy. J. Am. Chem. Soc. 126, 3390-3391.

Harper, S. M., Neil, L. C., and Gardner, K. H. (2003). Structural basis of a phototropin light 
switch. Science (80-. ). 301, 1541-1544.

Hatzfeld, M., and Franke, W. W. (1985). Pair formation and promiscuity of cytokeratins:

Formation in vitro of heterotypic complexes and intermediate-sized filaments by homologous and heterologous recombinations of purified polypeptides. J. Cell Biol. 101, 1826-1841.

Hatzfeld, M., and Weber, K. (1992). A synthetic peptide representing the consensus sequence motif at the carboxy-terminal end of the rod domain inhibits intermediate filament assembly and disassembles preformed filaments. J. Cell Biol. 116, 157-166.

Heasman, J., Torpey, N., and Wylie, C. (1992). The role of intermediate filaments in early Xenopus development studied by antisense depletion of maternal mRNA. Development, 119125.

Helfand, B. T. et al. (2011). Vimentin organization modulates the formation of lamellipodia. Mol. Biol. Cell 22, 1274-1289.

Herrmann, H., and Aebi, U. (2016). Intermediate Filaments: Structure and Assembly. Cold Spring Harb. Perspect. Biol. 8, a018242.

Herrmann, H., and Strelkov, S. V (2011). History and phylogeny of intermediate filaments: now in insects. BMC Biol. 9, 16.

Keller, R., Davidson, L. A., and Shook, D. R. (2003). How we are shaped: The biomechanics of gastrulation. Differentiation 71, 171-205.

Kelley, L. A., Mezulis, S., Yates, C. M., Wass, M. N., and Sternberg, M. J. E. (2015). The Phyre2 web portal for protein modeling, prediction and analysis. Nat. Protoc. 10, 845-858. Klymkowsky, M. W., Shook, D. R., and Maynell, L. a (1992). Evidence that the deep keratin filament systems of the Xenopus embryo act to ensure normal gastrulation. Proc. Natl. Acad. Sci. U. S. A. 89 , 8736-8740.

Kouklis, P. D., Traub, P., and Georgatos, S. D. (1992). Involvement of the consensus sequence motif at coil 2b in the assembly and stability of vimentin filaments. J. Cell Sci. 102, 31-41.

Lungu, O. I., Hallett, R. A., Choi, E. J., Aiken, M. J., Hahn, K. M., and Kuhlman, B. (2012). 
Designing photoswitchable peptides using the AsLOV2 domain. Chem. Biol. 19, 507-517.

Mariani, R. A., Paranjpe, S., Dobrowolski, R., and Weber, G. F. (2018). 14-3-3 recruits keratin intermediate filaments to mechanically sensitive cell-cell contacts. BioRxiv, 349092.

Martin, I., Leitner, A., Walther, P., Herrmann, H., and Marti, O. (2015). Model-based analysis of keratin intermediate filament assembly. J. Phys. D. Appl. Phys. 48, 375401.

Möglich, A., Ayers, R. A., and Moffat, K. (2009). Design and Signaling Mechanism of Light-

Regulated Histidine Kinases. J. Mol. Biol. 385, 1433-1444.

Murray, M. E., Mendez, M. G., and Janmey, P. A. (2014). Substrate stiffness regulates solubility of cellular vimentin. Mol. Biol. Cell 25, 87-94.

Nieuwkoop, P. D. (Pieter D. ., and Faber, J. (1994). Normal table of Xenopus laevis (Daudin) : a systematical and chronological survey of the development from the fertilized egg till the end of metamorphosis, Garland Pub.

Nutt, S. L., Bronchain, O. J., Hartley, K. O., and Amaya, E. (2001). Comparison of morpholino based translational inhibition during the development of Xenopus laevis and Xenopus tropicalis. Genesis 30, 110-113.

Parry, D. A. D., Steven, A. C., and Steinert, P. M. (1985). The coiled-coil molecules of intermediate filaments consist of two parallel chains in exact axial register. Biochem. Biophys. Res. Commun. 127, 1012-1018.

Peter, A., and Stick, R. (2015). Evolutionary aspects in intermediate filament proteins. Curr. Opin. Cell Biol. 32, 48-55.

Quinlan, R. A., Cohlberg, J. A., Schiller, D. L., Hatzfeld, M., and Franke, W. W. (1984). Heterotypic tetramer (A2D2) complexes of non-epidermal keratins isolated from cytoskeletons of rat hepatocytes and hepatoma cells. J. Mol. Biol. 178, 365-388.

Ridge, K. M. et al. (2016). Methods for Determining the Cellular Functions of Vimentin Intermediate Filaments. Methods Enzymol. 568, 389-426.

Rozario, T., Dzamba, B., Weber, G. F., Davidson, L. A., and DeSimone, D. W. (2009). The 
physical state of fibronectin matrix differentially regulates morphogenetic movements in vivo.

Dev. Biol. 327, 386-398.

Sanghvi-Shah, R., and Weber, G. F. (2017). Intermediate filaments at the junction of mechanotransduction, migration, and development. Front. Cell Dev. Biol. 5, 81.

Steinert, P. M. (1990). The two-chain coiled-coil molecule of native epidermal keratin intermediate filaments is a type I-type II heterodimer. J. Biol. Chem. 265, 8766-8774.

Steinert, P. M., Idler, W. W., and Zimmerman, S. B. (1976). Self-assembly of bovine epidermal keratin filaments in vitro. J. Mol. Biol. 108, 547-567.

Steinert, P. M., Marekov, L. N., Fraser, R. D. B., and Parry, D. A. D. (1993a). Keratin intermediate filament structure. Crosslinking studies yield quantitative information on molecular dimensions and mechanism of assembly. J. Mol. Biol. 230, 436-452.

Steinert, P. M., Marekov, L. N., and Parry, D. A. D. (1993b). Conservation of the Structure of Keratin Intermediate Filaments: Molecular Mechanism by Which Different Keratin Molecules Integrate into Preexisting Keratin Intermediate Filaments during Differentiation. Biochemistry 32, 10046-10056.

Strelkov, S. V, Herrmann, H., Geisler, N., Wedig, T., Zimbelmann, R., Aebi, U., and Burkhard, P. (2002). Conserved segments $1 \mathrm{~A}$ and $2 \mathrm{~B}$ of the intermediate filament dimer: their atomic structures and role in filament assembly. EMBO J. 21, 1255-1266.

Suzuki, K. ichi T., Suzuki, M., Shigeta, M., Fortriede, J. D., Takahashi, S., Mawaribuchi, S., Yamamoto, T., Taira, M., and Fukui, A. (2017). Clustered Xenopus keratin genes: A genomic, transcriptomic, and proteomic analysis. Dev. Biol. 426, 384-392.

Torpey, N., Wylie, C. C., and Heasman, J. (1992). Function of maternal cytokeratin in Xenopus development. Nature 357, 413-415.

Weber, G. F., Bjerke, M. A., and DeSimone, D. W. (2012). A mechanoresponsive cadherinkeratin complex directs polarized protrusive behavior and collective cell migration. Dev. Cell 22, $104-115$. 
Wu, Y. I., Frey, D., Lungu, O. I., Jaehrig, A., Schlichting, I., Kuhlman, B., and Hahn, K. M.

(2009). A genetically encoded photoactivatable Rac controls the motility of living cells. Nature 461, 104-108.

Zimmerman, S. P., Kuhlman, B., and Yumerefendi, H. (2016). Engineering and Application of LOV2-Based Photoswitches. Methods Enzymol. 580, 169-190.

Zwerger, M., Roschitzki-Voser, H., Zbinden, R., Denais, C., Herrmann, H., Lammerding, J., Grütter, M. G., and Medalia, O. (2015). Altering lamina assembly reveals lamina-dependent and -independent functions for A-type lamins. J. Cell Sci. 128, 3607-3620.

\section{Figure Legends}

Figure 1: Design of photoactivatable disruptor of keratin intermediate filaments.

(A) Schematic representation of primary structure of keratin IF proteins. The central rod domain, comprised of $\alpha$-helical coils IA, IB and coil II, are flanked by variable length head and tail domains at the $\mathrm{N}$ - and $\mathrm{C}$-termini, respectively. The red bar denotes the segment of keratin used in the constructed fusion proteins. (B) Sequence alignment of 2B2 segments of Xenopus laevis IF proteins including keratin 8, keratin 18/19, vimentin and nuclear lamins A, B and L. High homology exists across intermediate filaments. Keratin 8 2B2 has particularly high homology with vimentin and lamins. (C) Strategy for caging 2B2 mimetic peptide and mechanism for keratin network disruption. Upon irradiation with 458nm light the LOV- Ja is predicted to uncouple, making the 2B2 peptide available to bind to its dimerization partners keratin $18 / 19$ and thus disrupt keratin filaments. (D) Conserved amphipathic pattern in Ja-helix facilitates 
interactions between 2B2 and J $\alpha$-helix. Helical wheel projection of $\mathrm{J} \alpha$-helix, 2B2 and 2B2 appended to Ja-helix shown here were generated using Heliquest software molecular modeling. (E) Schematics of PA-dIF and CA-dIF modules comprise a Xenopus laevis Krt8 2B2 (22aa) mimetic peptide which is directly fused to the LOV-Ja Avena sativa photosensitive domain by a GS linker. CA-dIF module has an I379E point mutation in the J $\alpha$ domain.

Figure 2: Constitutively active disrupter of intermediate filaments (CA-dIF) disrupt keratin filaments in cultured HEK293T cells and MDCK cells.

The keratin network (green) was examined in HEK293T cells transfected with either mCherry PA-dIF (A) or mCherry CA-dIF (B), 24 hrs post-transfection. Cells were immunostained with pan-keratin antibody and counterstained with DAPI. Bars, $20 \mu \mathrm{m}$. MDCK cells were either mock transfected (control) (C) transfected with mCherry PA-dIF (D) or mCherry CA-dIF (E), 12 hrs post transfection. Confocal images of cells immunostained with pan-keratin antibody and counterstained with Hoechst dye display keratin network (green) organization and expression of PA-dIF and CA-dIF constructs (red) and nucleus (blue). Bars, $10 \mu \mathrm{m}$. White arrowheads show disruption of keratin filaments and white arrows show aberrant nuclear morphology. Yellow bar line in merged image indicates example region of line scans shown in graphs in (F) and (G). Distinct filaments are seen in control line scans as evidenced by periodic intensity fluctuations $(\mathbf{F})$, whereas keratin filaments in mCherry CA-dIF transfected cells are more aggregated and/or less distinct as shown by less varied intensity fluctuations (G).

Figure 3: Expression of CA-dIF binds to and disrupts keratin filaments in embryonic Xenopus cells.

Representative confocal images of Xenopus ectodermal explants (stage 11) expressing eGFPKrt8 and either mCherry (A), or mCherry-CA-dIF (B). Yellow arrowheads indicate the disruption 
of the keratin filaments in cells expressing mCherry-CA-dIF even at low levels. Bars, $10 \mu \mathrm{m}$. Xenopus embryos were microinjected with mCherry-CA-dIF (500 pg) mRNA at one cell stage in the animal hemisphere. (C) Lysates from embryos in gastrula stage were subjected to immunoprecipitation to isolate mCherry-CA-dIF complexes and separated by SDS-PAGE. Protein bands within the region outlined by the red box were excised, in-gel trypsinized and analyzed by LC-MS/MS. (D) Table summary of abundant proteins detected in LC-MS/MS samples.

Figure 4: Rapid subcellular disruption of keratin intermediate filaments by photoactivation of a genetically-encoded mimetic peptide.

Xenopus embryos were co-injected with eGFP-Krt8 and either mCherry or mCherry PA-dIF in the animal cap, targeting the presumptive ectoderm. Cells of the intact ectodermal animal cap explants expressing eGFP-Krt8 (green) and either the control or PA-dIF (red) were illuminated at different subcellular positions with $458 \mathrm{~nm}$ light over a $10 \mu \mathrm{m}$ diameter region (teal circle) for 30s intervals with image acquisition between photoirradiation events. Selected confocal images of time-lapse movies of the response of ectodermal progenitor cells to localized photoirradiation are shown. (A) mCherry controls show no keratin disruption nor aggregation either locally or throughout the cell. (B and $\mathbf{C}$ ) Two independent examples of light sensitive PA-dIF expressing cells exhibit local disruption and aggregation formation of keratin filaments. (D) An extended photoactivation regime induces complete collapse of the keratin network. Arrows indicate region of collapsing keratin network. Circles indicate region where the 458nm laser light was applied. Bars, $10 \mu \mathrm{m}$.

Figure 5: Keratin filaments are necessary for normal Xenopus embryo development.

Uninjected control embryos or embryos injected with control constructs (mCherry+ eGFP-Krt19) demonstrate normal morphological development from (A) gastrulation, (B) neurula, (C) early 
tailbud, (D) late tailbud, and (E) tadpole stages. Expression of mCherry CA-dIF in the ectodermal cells comprising the animal cap induces various developmental defects. Arrows point to defects such as regressed eye development (red arrow), defective yolk plug closure (green arrow), bifurcated tail (yellow arrow), and ventral edema (white arrow). Bars, 500 um. (F) Quantitative representations of normal and abnormal phenotypes.

Figure 6: Light induced activation of PA-dIF elicits abnormal Xenopus development. Fertilized Xenopus eggs uninjected or injected with PA-dIF at one cell stage were either protected from light or exposed to blue light. Phenotypes were assessed from gastrulation to tadpole stage. (A) Uninjected control embryos display a normal phenotype regardless of exposure to blue light. (B) Embryos were injected with 100 pg PA-dlF, (C) 175 pg PA-dIF, (D) 250 pg PA-dIF, (E) 500 pg PA-dIF. Embryos were grown under blue light conditions as indicated (+ or -). Developmental defects of open yolk plug/open dorsal side (green arrows), underdeveloped eye or no eye (red arrows), bifurcated tail (yellow arrows), ventral edema (white arrows) are indicated. Bars, $500 \mu \mathrm{m}$. (F) Quantitative representations of normal and abnormal phenotypes. 

Figure npt certified by peer review) is the author/funder, who has granted bioRxiv a license to display the preprint in perpetuity. It is made available A Head domain under aCC-BY-NC-ND 4 Rodernational license. Tail domain

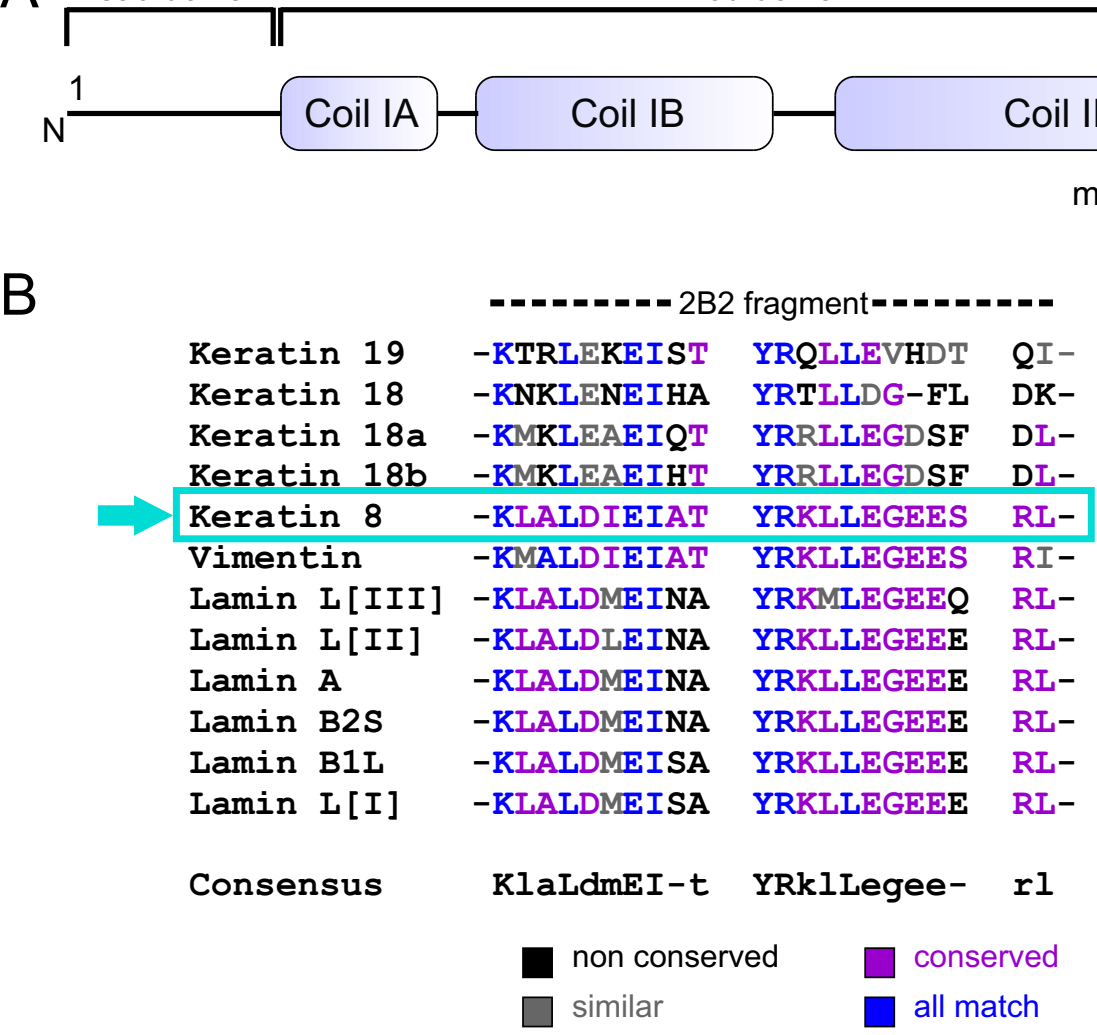

C

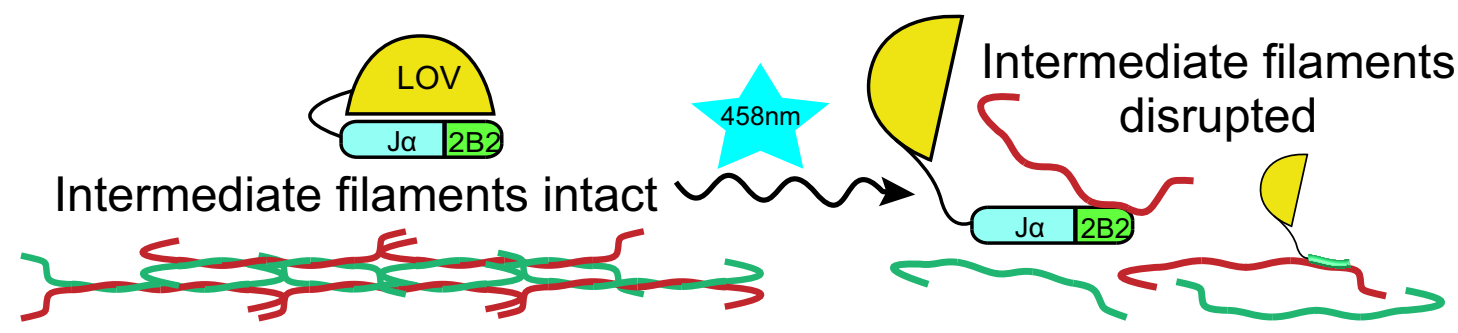

D
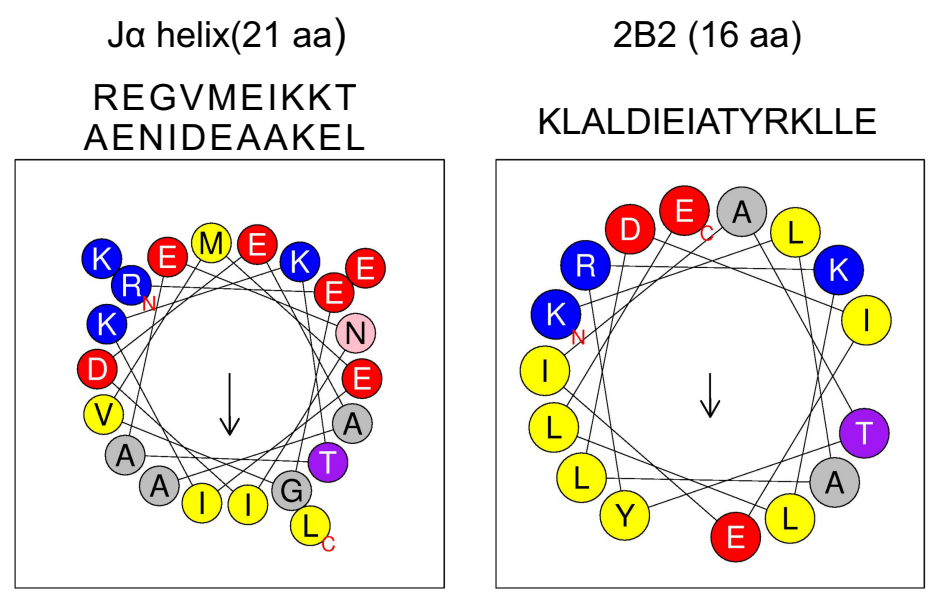

Ja-2B2 (37 aa)

$(389-410)$ 

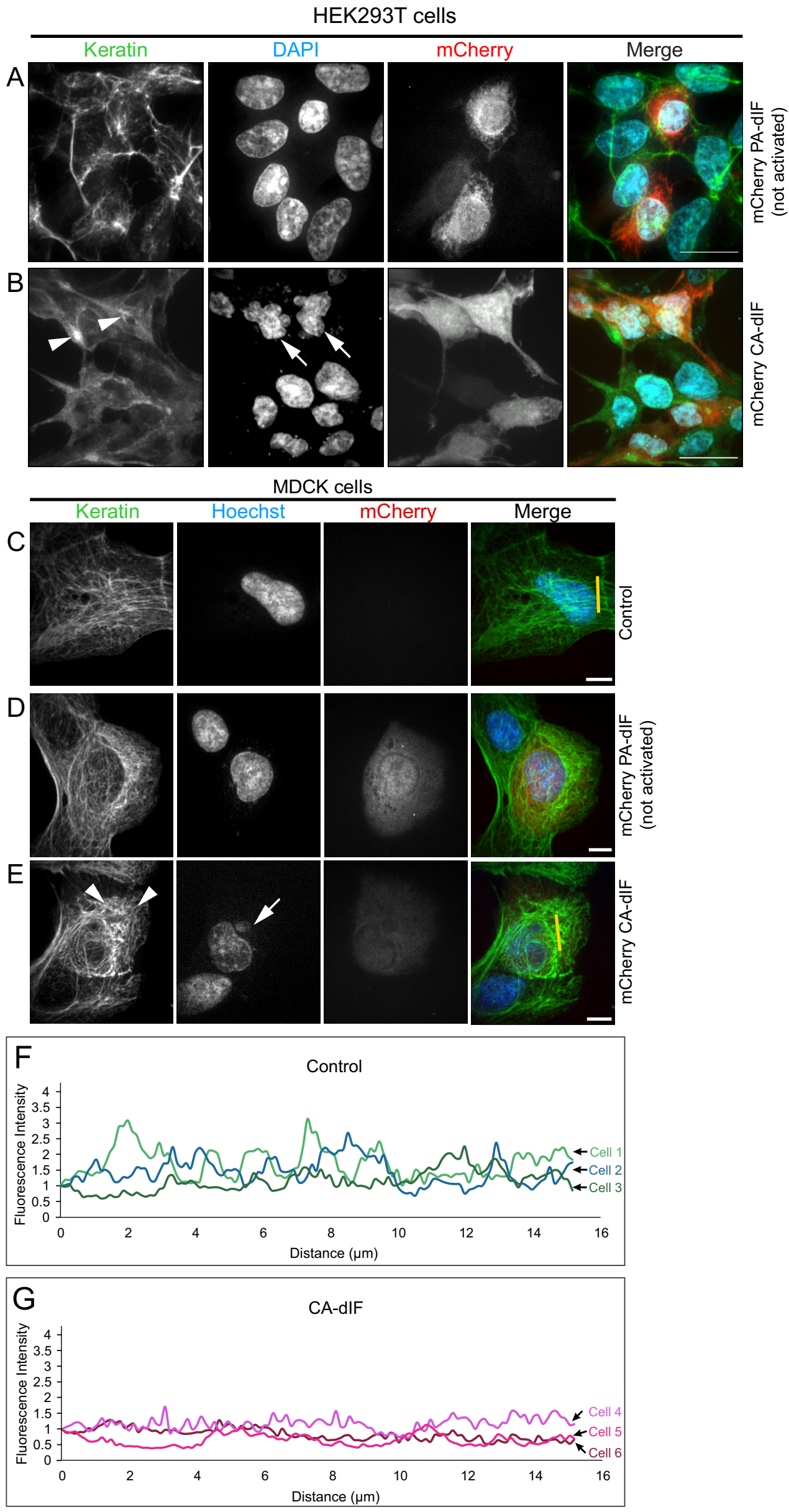

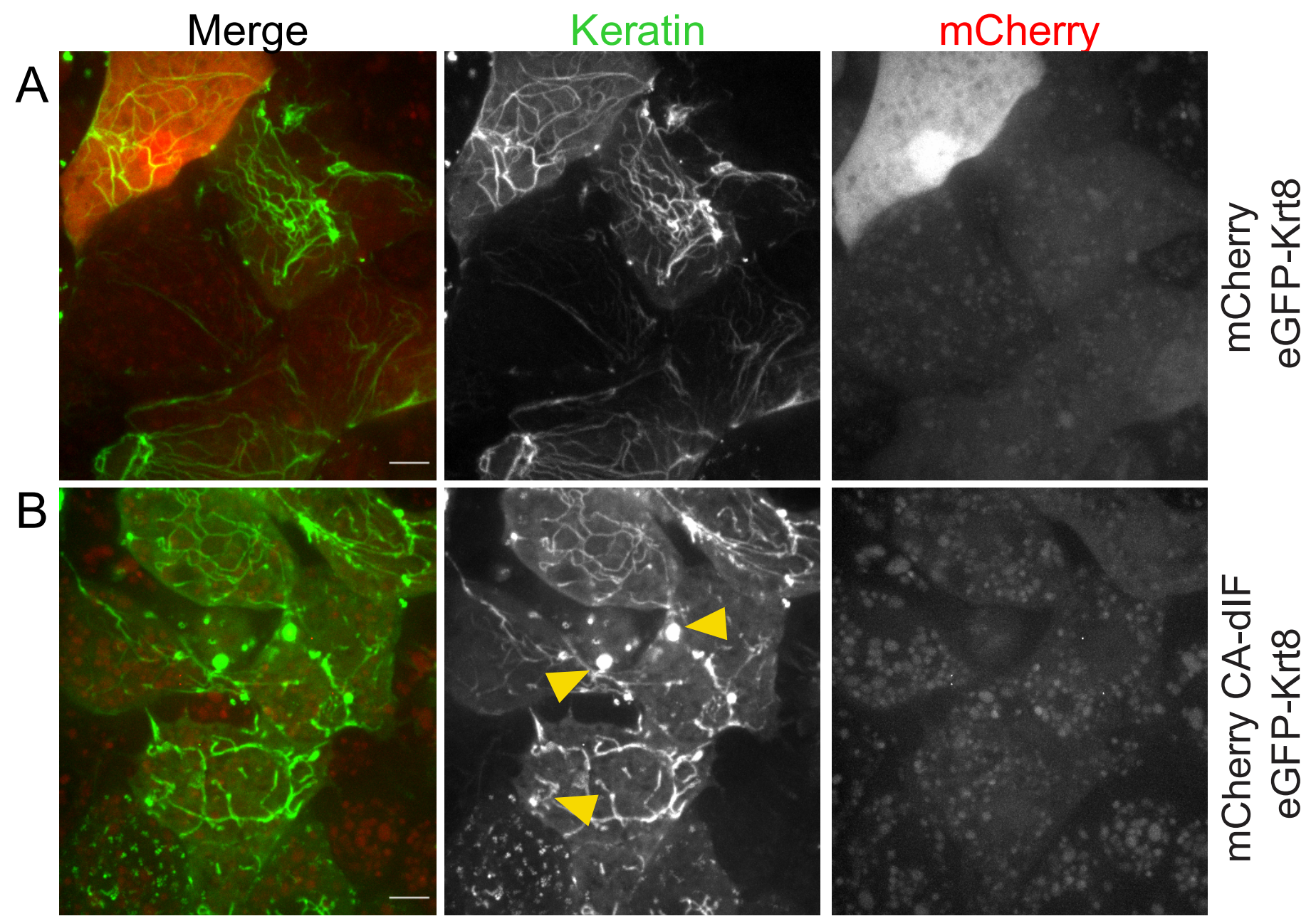

C Whole $\frac{\text { embryo lysate }}{+} \frac{\mathrm{IP}: \mathrm{mCherry}}{-}$
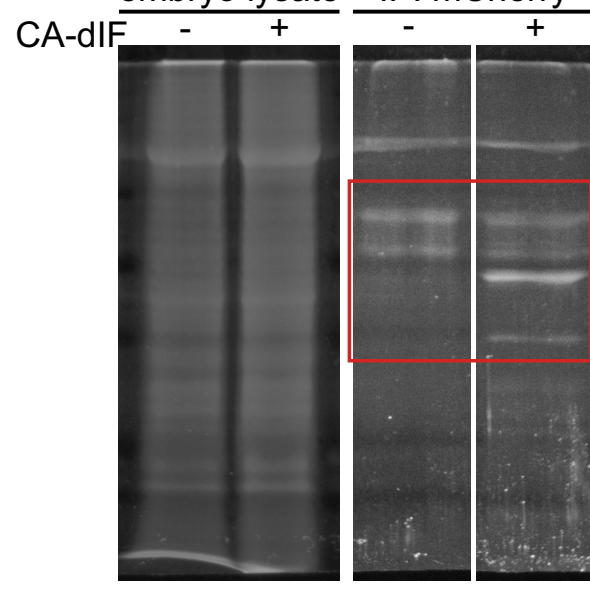

\begin{tabular}{|c|c|c|c|c|c|c|}
\cline { 2 - 7 } & kD \\
-100 & Description & $\begin{array}{c}\text { Gene } \\
\text { Symbol }\end{array}$ & $\begin{array}{c}\text { \# Unique } \\
\text { Peptides }\end{array}$ & $\begin{array}{c}\text { Spectra } \\
\text { counts } \\
\text { (Control) }\end{array}$ & $\begin{array}{c}\text { Spectra } \\
\text { counts } \\
\text { (IP:CA-dIF) }\end{array}$ & $\begin{array}{c}\text { Ratio } \\
\text { (CA-dIF/ } \\
\text { Control) }\end{array}$ \\
\cline { 2 - 7 }-50 & Keratin 18 & krt18.1.L & 19 & 23 & 43 & 1.8 \\
\cline { 2 - 7 }-37 & Tubulin $\alpha 1 \mathrm{a}$ & tuba1a & 7 & 14 & 23 & 1.6 \\
\cline { 2 - 7 } & Keratin 18 & krt18.1.S & 8 & 9 & 22 & 2.2 \\
\cline { 2 - 7 }-25 & $\begin{array}{c}\text { Ribosomal } \\
\text { Protein L3 }\end{array}$ & rpl3 & 12 & 6 & 17 & 2.4 \\
\cline { 2 - 7 } & $\begin{array}{c}\text { CNDP } \\
\text { Dipeptidase 2 }\end{array}$ & cndp2 & 5 & 5 & 11 & 1.9 \\
\hline
\end{tabular}




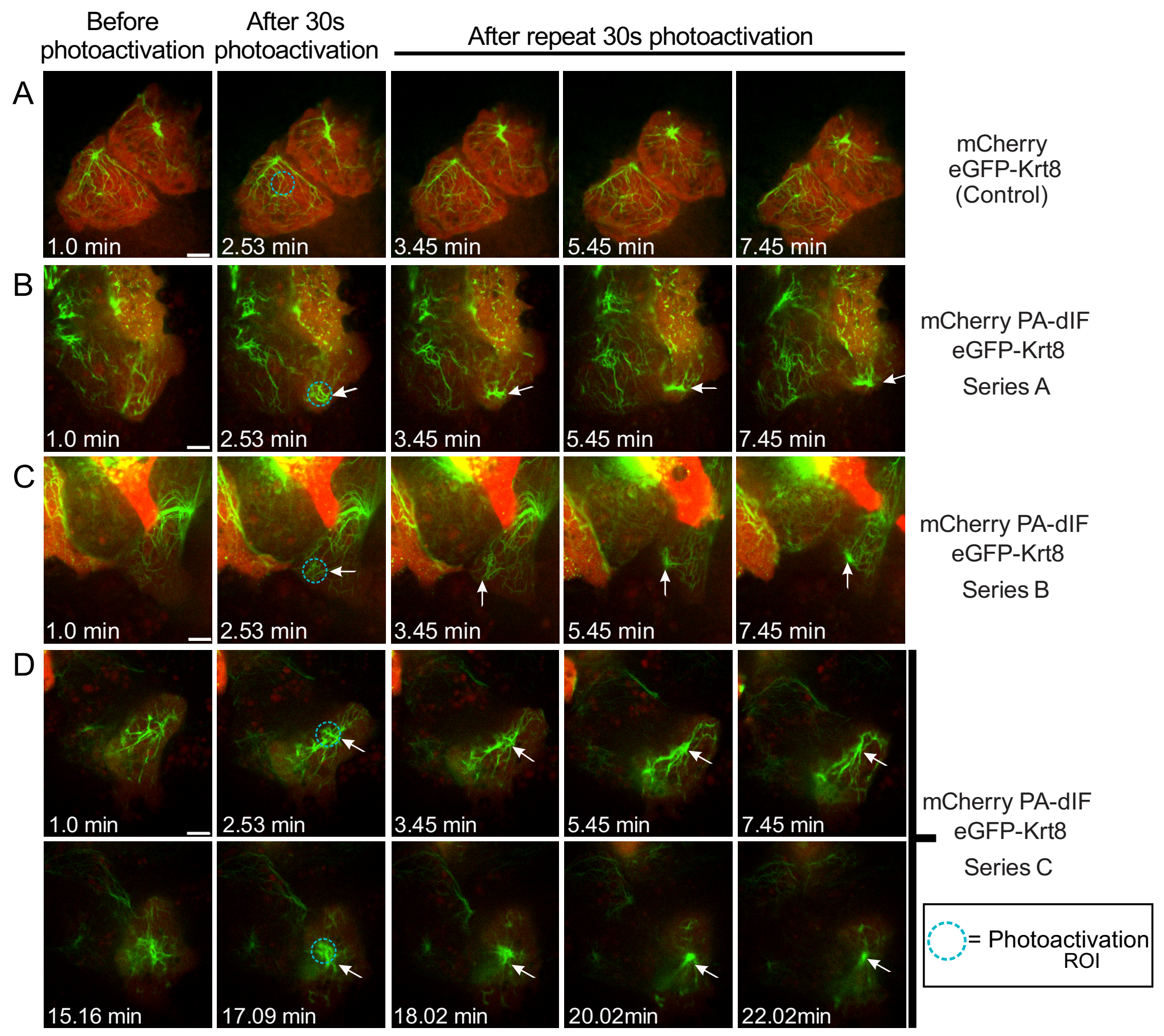




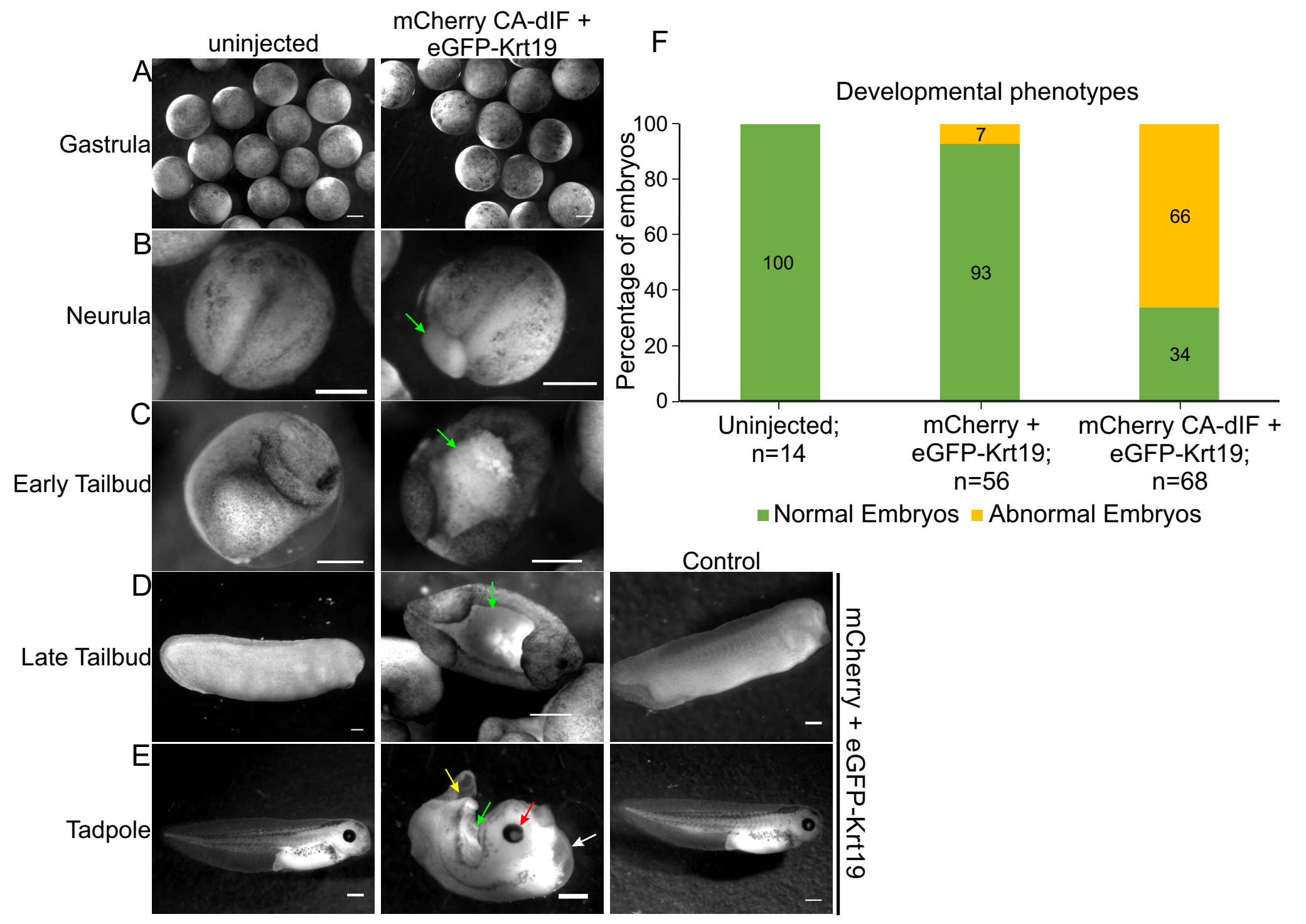


A uninjected

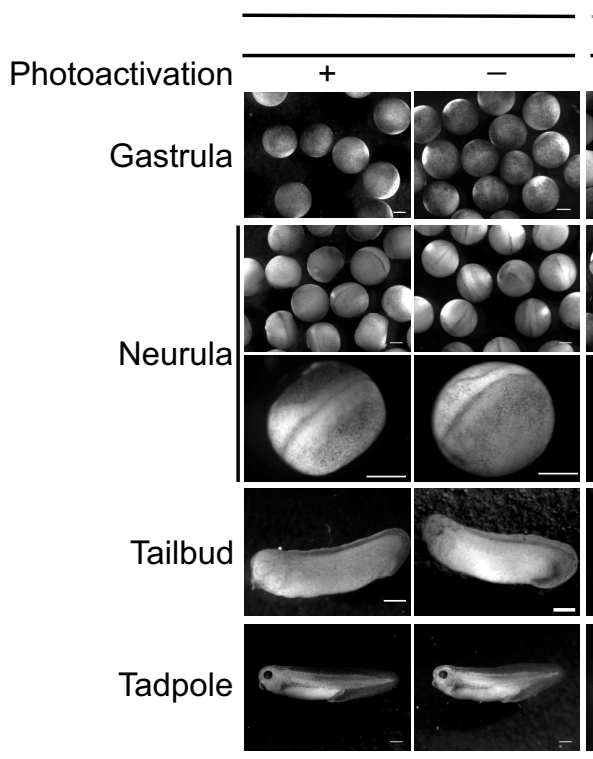

F

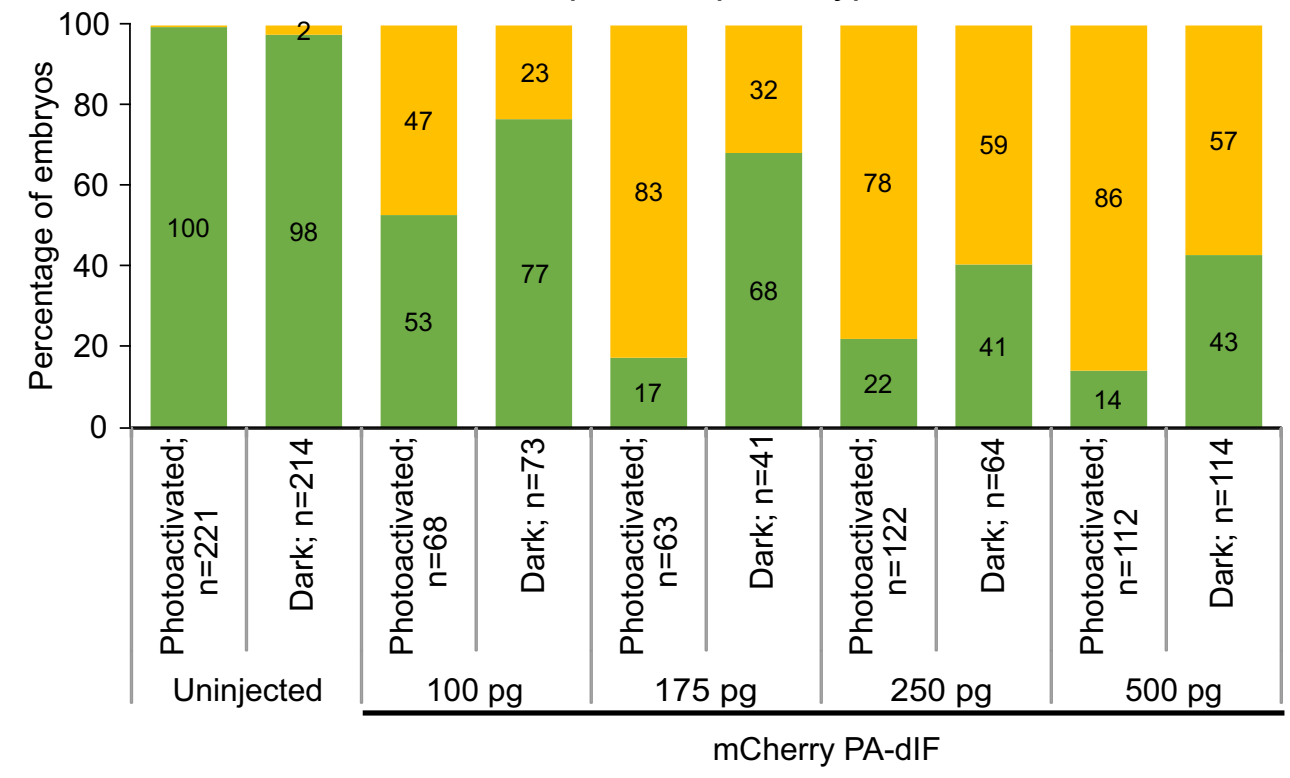

Normal embryos $\quad$ Abnormal embryos

mCherry PA-dIF
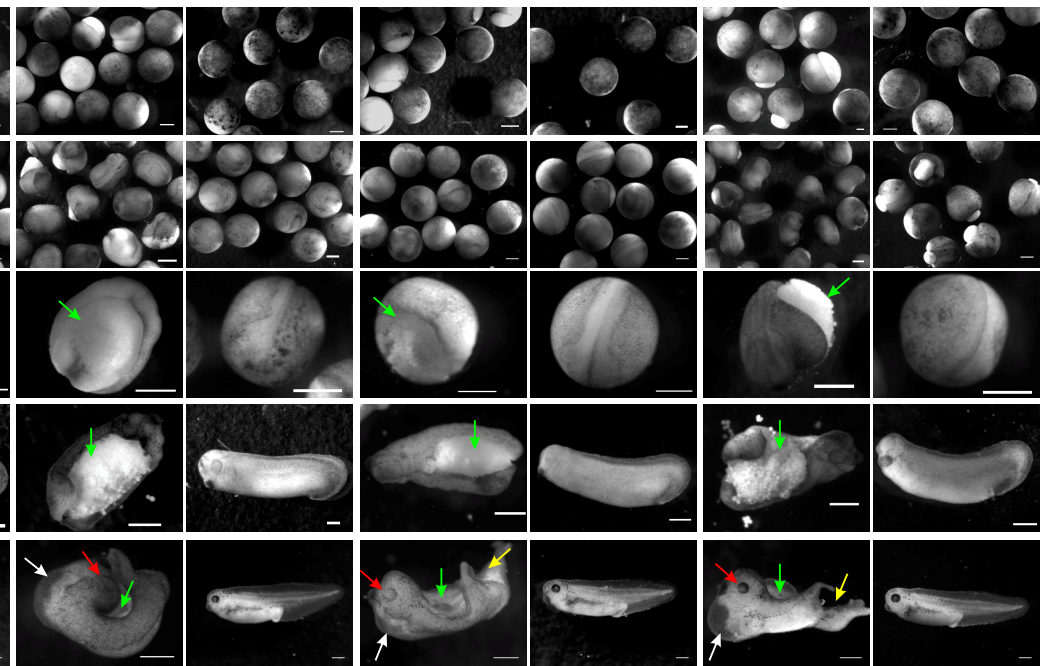

Developmental phenotypes

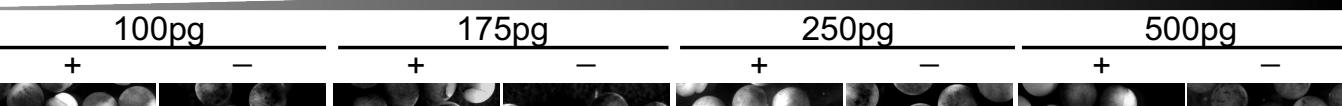
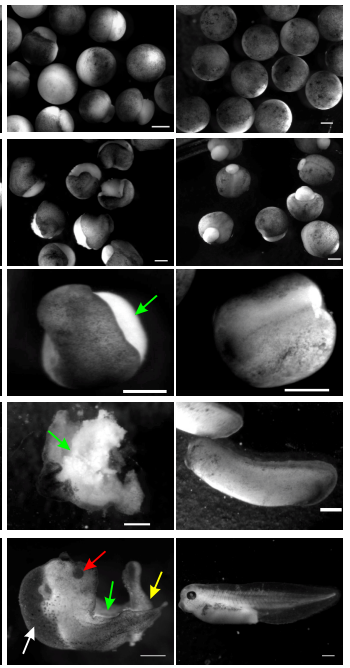


\section{Supplemental figure legends}

Figure S1: Sequence alignment of 2B2 segments of keratin 8 IF proteins.

Protein sequence alignment reveals that the $2 \mathrm{~B} 2$ peptide is highly conserved across different species including Xenopus, Canine, Bovine, Mouse and Human.

Figure S2: DNA and protein sequences for Photoactivatable disrupter of Intermediate Filaments.

DNA sequence for PA-dIF (A) and protein sequence for PA-dIF (B). The domains mCherry,

LOV-J $\alpha$ and 2B2 from Krt8 are color coded in red, blue and green respectively.

Figure S3: Secondary structure shows continuous $\alpha$-helical domain.

Fusion of $\mathrm{J} \alpha$ to $2 \mathrm{~B} 2$ retains the $\alpha$-helical structure in both PA-dIF (A) and CA-dIF (B).

Figure S4: Structural modelling shows a nearly contiguous $\alpha$-helical domain.

In both LOV-J $\alpha(\mathbf{A})$ and LOV-J $\alpha-2 B 2(B)$ the 3D structural analysis shows a continuous helical structure of $\mathrm{J} \alpha$ and also of J $\alpha$-2B2. However, in PA-dIF (mCherry LOV-J $\alpha-2 B 2$ ) (C), and CA-dIF (mCherry LOV-J $\alpha($ I379E)-2B2) (D) the addition of mCherry generates a loop and turn in J $\alpha-2 B 2$. The presence of mutation I379E in (D) induces a steric hindrance of the LOV-J $\alpha$ interaction not allowing the protein to fold properly. The protein is color coded from N-terminal (blue) to Cterminal (red). 


\section{Supplemental movies}

Movie S1: Unperturbed keratin filaments in control ectodermal cells. This movie corresponds to Figure 4A.

Movie S2: Localized photoactivation of PA-dIF induces disruption of keratin filaments-Series A. This movie corresponds to Figure 4B.

Movie S3: Localized photoactivation of PA-dIF induces disruption of keratin filaments-Series B. This movie corresponds to Figure 4C.

Movie S4: Repeated photoactivation of PA-dIF induces complete collapse of the keratin network-Series C. This movie corresponds to Figure 4D. 


$\begin{array}{llll} & & & \\ \text { Canine Keratin } 8 & \text {-KLALDIEIAT } & \text { YRKLLEGEES } & \text { RL- } \\ \text { Bovine Keratin } 8 & \text {-KLALDVEIAT } & \text { YRKLLEGEES } & \text { RL- } \\ \text { Mouse Keratin } 8 & \text {-KLALDIEITT } & \text { YRKLLEGEES } & \text { RL- } \\ \text { Human Keratin } 8 & \text {-KLALDIEIAT } & \text { YRKLLEGEES } & \text { RL- } \\ \text { Xenopus Keratin } 8 & \text {-KLALDIEIAT } & \text { YRKLLEGEES } & \text { RL- } \\ \text { Consensus } & & \\ & \text { KLALDiEIaT } & \text { YRKLLEGEES } & \text { RL } \\ & & \\ \text { non conserved } & \square \text { conserved } & \end{array}$




\section{Supplemental Figure 2.}

\section{A DNA Sequence for Photoactivatable disrupter of Intermediate Filaments (PA-dIF)}
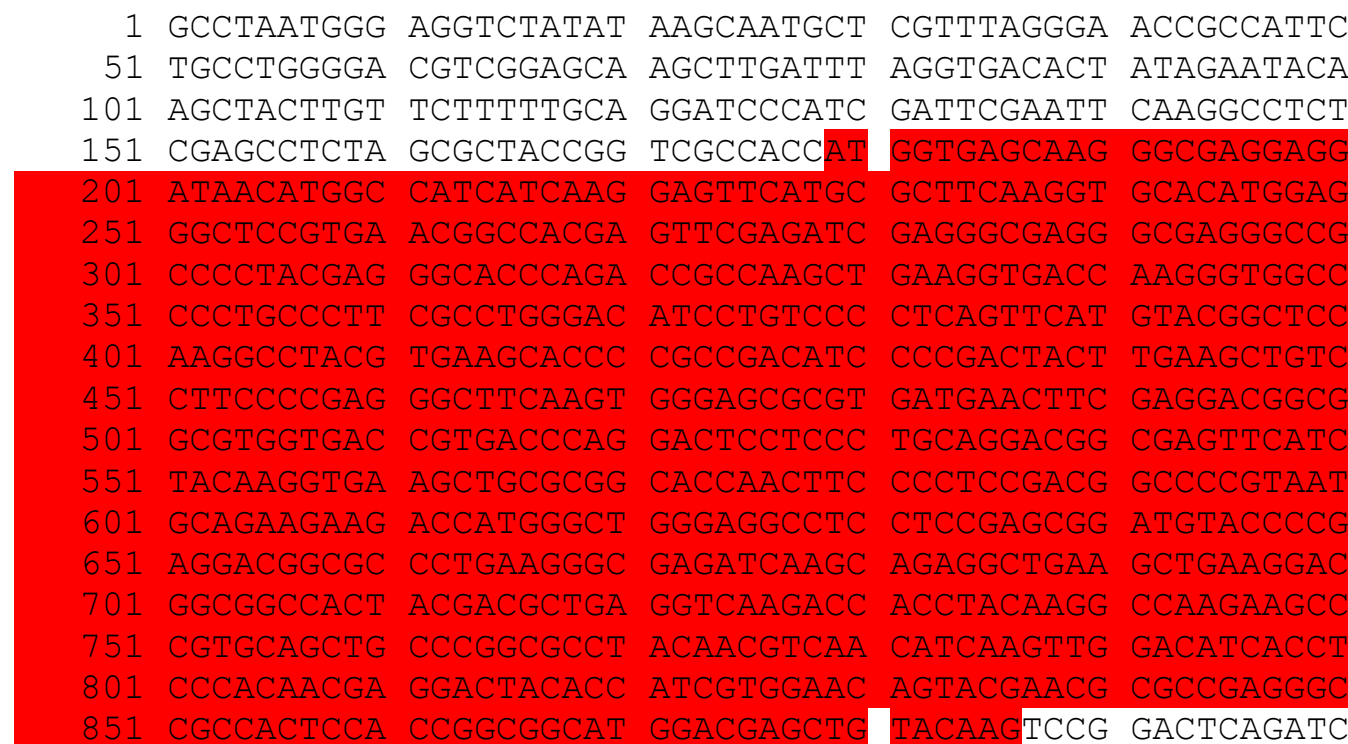

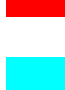

\section{TGGATCACTG}

951 CTGACCCAAG

1001 TTGCAGTTGA

1051 GTTTCTACAA GGTCCTGAAA CTGATCGCGC GA

1101 ATGCCATAGA TAACCAAACA GAGGTCACTG

1151 AAGAGTGGTA AAAAGTTCTG GAACCTCTTT

1201 TCAGAAGGGA GATGTCCAGT ACTTTATTGG GGT

1251 AGCACGTGCG AGATGCTGCC GAGAGAGAGG GAG

1301 ACTGCAGAAA ATATTGATGA GGCGGCAAAA GAG

1351 TATCGAGATC GCCACCTACA GGAAACTGCT GGA

1401 TGTGACCCGG GTGACTCGAG CCTCTAGAAC TATAGTGAGT CGTATTACGT

1451 AGATCCAGAC ATGATAAGAT ACATTGATGA GTTTGGACAA ACCACAACTA

1501 GAATGCAGTG AAAAAAATGC TTTATTTGTG AAATTTGTGA TGCTATTGCT

1551 TTATTTGTAA CCATTATAAg CTGCAATAAA CAAGTTAACA ACAACAATTG

1601 CATTCATTTT ATGTTTCAGG TTCAGGGGGA GGTGTGGGAG GTTTTTTAAT

1651 TCGCGGCCGC GGCGCCAATG CATTGGGCCC GGTACCCAGC TTTTGTTCCC

1701 TTTAGTGAGG GTTAATTGCG CGCTTGGCGT AATCATGGTC ATAGCTGTTT

1751 CCTGTGTGAA ATTGTTATCC GCTCACAATT CCACACAACA TACGAGCCGG

1801 AAGCATAAAG TGTAAAGCCT GGGGTGCCTA ATGAGTGAGC TAACTCACAT

1851 TAATTGCGTT GCGCTCACTG CCCGCTTTCC AGTCGGGAAA CCTGTCGTGC

1901 CAGCTGCATT AATGAATCGG CCAACGCGCG GGGAGAGGCG GTTTGCGTAT

1951 TGGGCGCTCT TCCGCTTCCT CGCTCACTGA CTCGCTGCGC TCGGTCGTTC

2001 GGCTGCGGCG AGCGGTATCA GCTCACTCAA AGGCGGTAAT ACGGTTATCC

2051 ACAGAATCAG GGGATAACGC AgGAAAgAAC ATGTGAGCAA AAgGCCAGCA

2101 AAAGGCCAGG AACCGTAAAA AGGCCGCGTT GCTGGCGTTT TTCCATAGGC

2151 TCCGCCCCCC TGACGAGCAT CACAAAAATC GACGCTCAAG TCAGAGGTGG

2201 CGAAACCCGA CAGGACTATA AAGATACCAG GCGTTTCCCC CTGGAAGCTC

2251 CCTCGTGCGC TCTCCTGTTC CGACCCTGCC GCTTACCGGA TACCTGTCCG

2301 CCTTTCTCCC TTCGGGAAGC GTGGCGCTTT CTCATAGCTC ACGCTGTAGG 
bioRxiv preprint doi: https://doi.org/10.1101/484246; this version posted November 30, 2018. The copyright holder for this preprint (which was not certified by peer review) is the author/funder, who has granted bioRxiv a license to display the preprint in perpetuity. It is made available under aCC-BY-NC-ND 4.0 International license.

2351 tATCTCAgTt CGgTGTAgGt CGTTCGCTCC AAgCTGgGCT GTGTGCACGA 2401 ACCCCCCGTT CAGCCCGACC GCTGCGCCTT ATCCGGTAAC TATCGTCTTG 2451 AGTCCAACCC GGTAAGACAC GACTTATCGC CACTGGCAGC AGCCACTGGT 2501 AACAGGATTA GCAGAGCGAg GTATGTAGGC GGTGCTACAg AGTTCTTGAA 2551 GTGGTGGCCT AACTACGGCT ACACTAGAAG GACAGTATTT GGTATCTGCG 2601 CTCTGCTGAA GCCAGTTACC TTCGGAAAAA GAGTTGGTAG CTCTTGATCC 2651 GGCAAACAAA CCACCGCTGG TAGCGGTGGT TTTTTTGTTT GCAAGCAGCA 2701 GATTACGCGC AGAAAAAAAG GATCTCAAGA AGATCCTTTG ATCTTTTCTA 2751 CGGGGTCTGA CGCTCAGTGG AACGAAAACT CACGTTAAgG GATTTTGGTC 2801 ATGAGATTAT CAAAAAGGAT CTTCACCTAG ATCCTTTTAA ATTAAAAATG 2851 AAGTTTTAAA TCAATCTAAA GTATATATGA GTAAACTTGG TCTGACAGTT 2901 ACCAATGCTT AATCAGTGAG GCACCTATCT CAGCGATCTG TCTATTTCGT 2951 TCATCCATAG TTGCCTGACT CCCCGTCGTG TAGATAACTA CGATACGGGA 3001 GGGCTTACCA TCTGGCCCCA GTGCTGCAAT GATACCGCGA GACCCACGCT 3051 CACCGGCTCC AGATTTATCA GCAATAAACC AGCCAGCCGG AAGGGCCGAG 3101 CGCAGAAGTG GTCCTGCAAC TTTATCCGCC TCCATCCAGT CTATTAATTG 3151 TtgCCGGGAA GCTAGAgtAA GTAGTTCGCC AGTTAATAGT TTGCGCAACG 3201 TTGTTGCCAT TGCTACAGGC ATCGTGGTGT CACGCTCGTC GTTTGGTATG 3251 GCTTCATTCA GCTCCGGTTC CCAACGATCA AGGCGAGTTA CATGATCCCC 3301 CATGTTGTGC AAAAAAGCGG TTAGCTCCTT CGGTCCTCCG ATCGTTGTCA 3351 GAAGTAAGTT GGCCGCAGTG TTATCACTCA TGGTTATGGC AGCACTGCAT 3401 AATTCTCTTA CTGTCATGCC ATCCGTAAGA TGCTTTTCTG TGACTGGTGA 3451 GTACTCAACC AAGTCATTCT GAGAATAGTG TATGCGGCGA CCGAGTTGCT 3501 CTTGCCCGGC GTCAATACGG GATAATACCG CGCCACATAg CAGAACTTTA 3551 AAAGTGCTCA TCATTGGAAA ACGTTCTTCG GGGCGAAAAC TCTCAAGGAT 3601 CTTACCGCTG TTGAGATCCA GTTCGATGTA ACCCACTCGT GCACCCAACT 3651 GATCTTCAGC ATCTTTTACT TTCACCAGCG TTTCTGGGTG AGCAAAAACA 3701 GGAAGGCAAA ATGCCGCAAA AAAGGGAATA AGGGCGACAC GGAAATGTTG 3751 AATACTCATA CTCTTCCTTT TTCAATATTA TTGAAGCATT TATCAGGGTT 3801 ATTGTCTCAT GAGCGGATAC ATATTTGAAT GTATTTAGAA AAATAAACAA 3851 ATAGGGGTTC CGCGCACATT TCCCCGAAAA GTGCCACCTA AATTGTAAGC 3901 GTTAATATTT TGTTAAAATT CGCGTTAAAT TTTTGTTAAA TCAGCTCATT 3951 TTTTAACCAA TAGGCCGAAA TCGGCAAAAT CCCTTATAAA TCAAAAGAAT 4001 AGACCGAGAT AGGGTTGAGT GTTGTTCCAG TTTGGAACAA GAGTCCACTA 4051 TTAAAGAACG TGGACTCCAA CGTCAAAGGG CGAAAAACCG TCTATCAGGG 4101 CGATGGCCCA CTACGTGAAC CATCACCCTA ATCAAGTTTT TTGGGGTCGA 4151 GGTGCCGTAA AGCACTAAAT CGGAACCCTA AAGGGAGCCC CCGATTTAGA 4201 GCTTGACGGG GAAAGCCGGC GAACGTGGCG AGAAAGGAAG GGAAGAAAGC 4251 GAAAGGAGCG GGCGCTAGGG CGCTGGCAAG TGTAGCGGTC ACGCTGCGCG 4301 TAACCACCAC ACCCGCCGCG CTTAATGCGC CGCTACAGGG CGCGTCCCAT 4351 TCGCCATTCA GGCTGCGCAA CTGTTGGGAA GGGCGATCGg TGCGGGCCTC 4401 TTCGCTATTA CGCCAGTCGA CCATAgCCAA TTCAATATGg CGTATATGGA 4451 CTCATGCCAA TTCAATATGG TGGATCTGGA CCTGTGCCAA TTCAATATGG 4501 CGTATATGGA CTCGTGCCAA TTCAATATGG TGGATCTGGA CCCCAGCCAA 4551 TtCAATATGG CGGACTTGGC ACCATGCCAA tTCAATATGG CGGACTTGGC 4601 ACTGTGCCAA CTGGGGAGGg GTCTACTTGG CACGGTGCCA AGTTTGAGGA 4651 GGGGTCTTGG CCCTGTGCCA AGTCCGCCAT ATTGAATTGG CATGGTGCCA 4701 ATAATGGCGg CCATATTGGC TATATGCCAg GATCAAtATA TAgGCAATAT 4751 CCAATATGGC CCTATGCCAA TATGGCTATT GGCCAGGTTC AATACTATGT 4801 ATTGGCCCTA TGCCATATAg TATTCCATAT ATGGGTTTTC CTATTGACGT 4851 AGATAGCCCC TCCCAATGGG CGGTCCCATA TACCATATAT GGGGCTTCCT 4901 AATACCGCCC ATAGCCACTC CCCCATTGAC GTCAATGGTC TCTATATATG 4951 GTCTTTCCTA TTGACGTCAT ATGGGCGGTC CTATTGACGT ATATGGCGCC 5001 TCCCCCATTG ACGTCAATTA CGgTAAATGg CCCGCCTGGC TCAATGCCCA 
bioRxiv preprint doi: https://doi.org/10.1101/484246; this version posted November 30, 2018. The copyright holder for this preprint (which was not certified by peer review) is the author/funder, who has granted bioRxiv a license to display the preprint in perpetuity. It is made available under aCC-BY-NC-ND 4.0 International license.

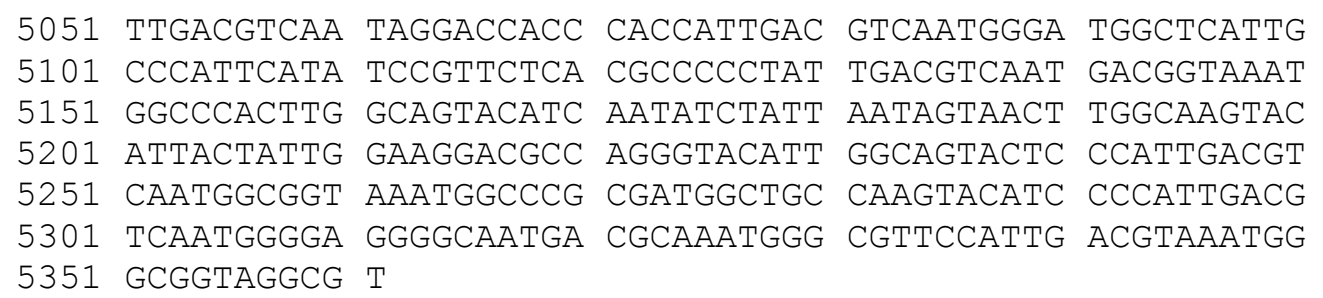

:mCherry

:LOV-Ja

:2B2 xKrt8

ATT :mutated to GAG for CA-dIF (constitutive active) construct

\section{B Protein Sequence for Photoactivatable disrupter of Intermediate Filaments (PA-dIF)}

$\mathrm{MW}=46420$ dalton

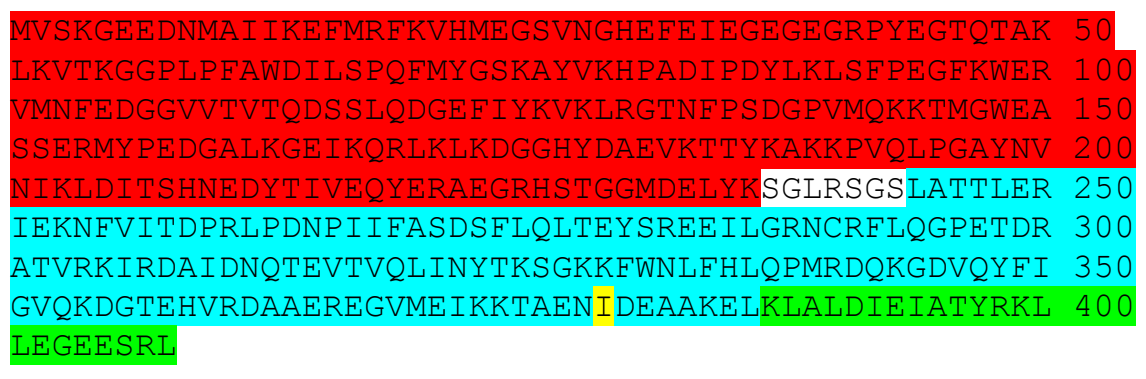

I379E $=$ CA-dIF 
bioRxiv preprint doi: https://doi org/10 1101/484246; this version posted November 30 2018. The copyright holder for this preprint (which was

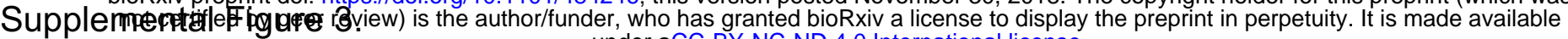
under aCC-BY-NC-ND 4.0 International license.

\section{A PA-dIF}

Sequence RDAAEREGVMEI KKTAENI DEAAKELKLALDIEI ATYRKLLEGEESRL Secondary structure

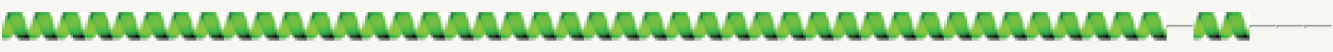
confidence

Disorder

Disorder

confidence

\section{B CA-dIF}

Sequence RDAAEREGVME I KKTAENEDEA A KELKLALDI E I ATYRKLLEGEESRL

\section{Secondary}

structure

confidence

Disorder

Disorder

confidence

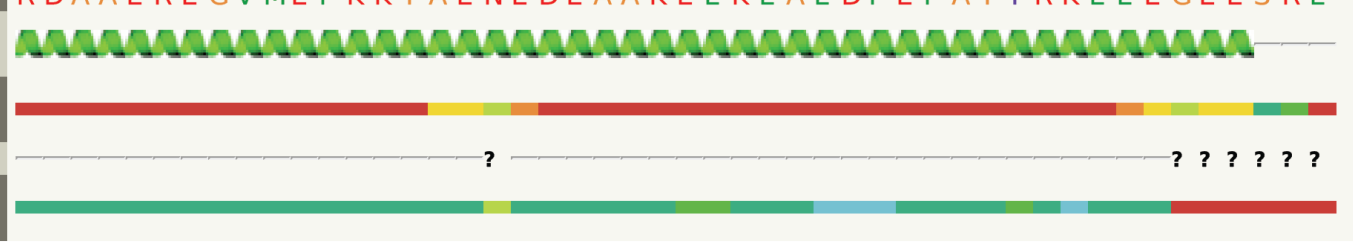

Confidence Key

$\operatorname{High}(9)$ 
bioRxiv preprint doi: https://doi.org/10.1101/484246; this version posted November 30,2018 . The copyright holder for this preprint (which was

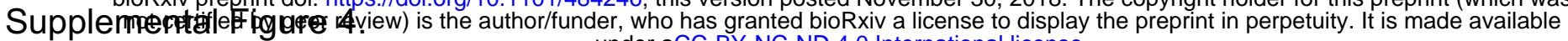
under aCC-BY-NC-ND 4.0 International license.

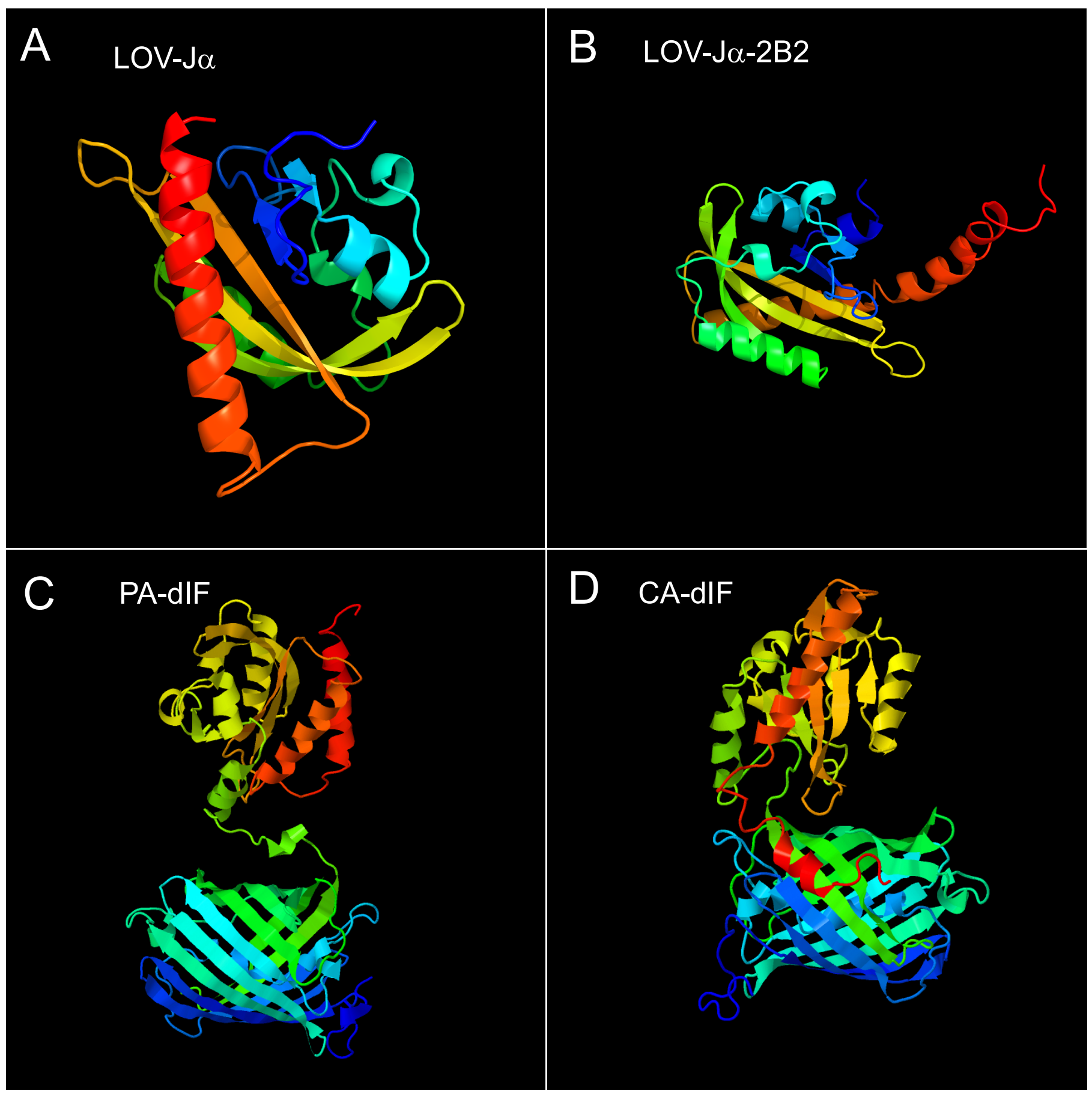

